\title{
Resiliência e Transformação do Comércio: O caso português
} Resilience and Trade Transformation: The Portuguese case

\author{
José António Rousseau, Universidade Europeia, Portugal \\ (jose.rousseau@universidadeeuropeia.pt)
}

Resumo: Como compreender os mecanismos ou os processos que, empresas retalhistas independentes de Lisboa, criadas ao longo do século XIX e algumas até anteriores conseguiram dobrar o século XX e chegar aos dias de hoje ainda saudáveis, lucrativas e com potencial para o futuro? Tal situação só pode ser explicada pela fantástica capacidade de resiliência demonstrada na sua atividade ao longo de quase dois séculos. Mas o que é, no que consiste a resiliência e quais as suas capacidades e fatores potencializadores? Determinaremos se qualidades como a flexibilidade, a resistência, a renovação, a redundância, a agilidade e a adaptação são fatores constitutivos da resiliência dos formatos comerciais retalhistas independentes. Fatores como a transição familiar intergerações e a ligação da atividade retalhista a uma indústria não são determinantes, sendo mesmo os fatores com menor potencial de resiliência encontrados, facto que, em certa medida, face à perceção pacífica existente, constitui uma surpresa deste estudo. Em contrapartida, os fatores internos da atividade comercial como, a localização, a natureza ulta especializada e a qualidade do serviço e do atendimento constituem-se como fortes fatores potencializadores da resiliência do retalho independente centenário de Lisboa. Este estudo demonstra, na esteira da conclusão formulada por Moschis, Curasi e Bellenger (2004), relativamente ao comércio em geral, que a idade e o género têm pouco a ver com os motivos de compra no comércio centenário. Por outro lado, também demostra que as orientações para a compra influenciam a perceção relativamente aos atributos da loja retalhista a escolher, sendo esta influência explicada por diferentes graus de abstração e emoção por parte do. De igual modo fica demonstrado que atributos, como a localização, a proximidade da loja, a existência de parqueamento, o conhecimento da loja e facilidade em encontrar o que se pretende, são motivos de conveniência que induzem o consumidor à decisão de compra.

Palavras-chave: retalho independente, resiliência, comércio, distribuição, Motivações de consumo

\begin{abstract}
How can we understand the mechanisms or the processes that, independent retail companies in Lisbon, created throughout the 19th century and some even before, managed to bend the 20th century and reach the present day still healthy, profitable and with potential for the future? Such a situation can only be explained by the fantastic resilience demonstrated in their activity over almost two centuries. But what is resilience, what does it consist of, and what are its capabilities and enabling factors? We will determine whether
\end{abstract}


qualities such as flexibility, resilience, renewal, redundancy, agility and adaptation are constitutive factors in the resilience of independent retail business formats. Factors such as intergenerational family transition and the linking of retail activity to an industry are not determinants, and are even the factors with the lowest potential for resilience found, which to some extent, given the existing peaceful perception, is a surprise of this study. On the other hand, the internal factors of the commercial activity such as location, the ulta specialized nature and the quality of service and attendance are strong potential resilience factors for Lisbon's centenary independent retail. This study demonstrates, in line with the conclusion drawn by Moschis, Curasi and Bellenger (2004), concerning commerce in general, that age and gender have little to do with purchase motives in centennial commerce. On the other hand, it also demonstrates that purchase orientations influence the perception regarding the attributes of the retail store to be chosen, this influence being explained by different degrees of abstraction and emotion on the part of the consumer. Likewise, it is shown that attributes such as location, proximity to the store, parking, knowledge of the store and ease of finding what one wants, are reasons of convenience that induce the consumer to make the purchase decision.

Keywords: independent retailing, resilience, trade, distribution

\section{Introdução}

A evolução do comércio ao longo dos anos tem sido um fenómeno complexo e, por vezes, contraditório, tendo já sido qualificado na esteira de Schumpeter como um processo de destruição criativa (Kotler \& Dubois 1994). Muitas teorias têm sido explanadas para justificar esta dinâmica transformista, mas nenhuma até agora conseguiu de forma cabal e completa prever ou explicar as alterações verificadas. A energia (Einstein), a matéria (Lavoisier) e também o comércio (Rousseau, 2008), possuem a propriedade da inércia ou massa, traduzida por Lavoisier, de forma genial e sintética, na afirmação de que "Na natureza, nada se perde, nada se cria, tudo se transforma".

A noção de resiliência foi usada originalmente pelo cientista inglês Thomas Young (1807) e adoptada pela Física, que a utiliza para caracterizar a propriedade através da qual a energia armazenada num corpo deformado é devolvida quando cessa a tensão causadora da deformação elástica, isto é, a capacidade concreta de conseguir voltar ao seu estado inicial e natural de excelência, superando uma situação critica. As ciências sociais tomaram este conceito emprestado (Holling, 1973) definindo resiliência como a capacidade, de um indivíduo ou de uma organização, para lidar com problemas, superar obstáculos ou resistir à pressão de situações adversas sem entrar em crise e conseguindo ultrapassá-las. Esta verdadeira arte de transformar toda a energia de um problema numa solução criativa (Grapeia, 2004) consiste, no fundo, no equilíbrio entre a tensão e a capacidade de resistir e atingir um nível mais elevado de consciência, que aporta mudanças comportamentais para lidar e vencer os obstáculos do dia-a-dia. Numa empresa comercial, a resiliência é a capacidade de promover as mudanças necessárias para atingir os seus objetivos, de manter as competências e habilidades, mesmo diante das adversidades, de antecipar crises, prever adversidades e saber preparar-se o melhor possível (Rousseau, 2011). 


\section{Desenho metodológico do estudo}

Este estudo foi organizado segundo um desenho metodológico longitudinal de acordo com um plano de investigação baseado num modelo linear sequencial bifásico (Fig.1).

Fig. 1 - Modelo Linear sequencial Bifásico.

\begin{tabular}{|c|c|}
\hline Fase 1 - Exploratória & Fase 2 - Confirmatória \\
\hline $\begin{array}{l}\text { - Análise de dados secundários } \\
\text { - Entrevistas com opinion } \\
\text { makers/especialistas } \\
\text { - Entrevistas qualitativas, semi-estruturas, } \\
\text { em profundidade com } 47 \text { retalhistas } \\
\text { independentes centenários }\end{array}$ & $\begin{array}{l}\text { Entrevistas individuais com uma } \\
\text { amostra de } 472 \text { consumidores } \\
\text { residentes em Lisboa }\end{array}$ \\
\hline
\end{tabular}

\section{$O$ conceito de resiliência}

Uma definição usada na engenharia considera resiliência como a tendência do material para regressar à sua forma original após a remoção de uma tensão que produziu deformação elástica (Merriam-Webster, 2007). Nas ciências da natureza e do ambiente, a definição padrão de resiliência considera-a como a capacidade de um ecossistema se recuperar de uma perturbação, mantendo a diversidade, integridade e processos ecológicos (Folke et al., 2004) ou como a capacidade dos ecossistemas para absorver e responder a fatores de perturbação (Holling, 1973). Em psicologia, resiliência tem sido caracterizada como a capacidade positiva das pessoas para lidar com o stress e eventos catastróficos e seu nível de resistência face a futuros eventos negativos. Na Física, resiliência tem sido descrita como a propriedade física de um material de após sofrer uma deformação voltar à sua forma original. Nas redes informáticas, resiliência tem sido expressa como a capacidade de fornecer e manter um nível aceitável de serviço face às falhas e desafios suscitados por uma operação normal (Hollnagel et al., 2006). Na engenharia de sistemas, resiliência tem sido definida como a capacidade do sistema para suportar uma perturbação e recuperar, passando por uma mudança, mas mantendo a mesma funcionalidade (Gibbs, 2009). Por ser pacífico considerar o conceito da adaptabilidade crucial nos sistemas ligados à vida, Fiksel (2003), por este conceito inspirado, propõe como quatro principais características de sistemas resilientes, além da já referida adaptabilidade, a diversidade, a eficiência e a coesão. $\mathrm{Na}$ área da gestão, algumas abordagens têm sido também feitas por alguns autores segundo ângulos diferentes, nomeadamente, pela perspetiva da liderança (Stolz, 2004) e dos recursos humanos (Coutu, 2002) assim como, em muitas outras áreas como a teoria económica, a psicologia e a sociologia (Holling, 1973; Arthur, 1999; Mallak, 1999; Adger, 2000; Callaway et al., 2000; Carpenter et al., 2001; Starr et al., 2003; Bonanno, 2004).

Como conceito chave a resiliência aparece ainda em muitas áreas relacionadas com sistemas complexos, tais como, as empresas, a logística e os ecossistemas (Carpenter et al., 2001; He, 2008) sendo nestas perspectivas, considerada como um atributo inerente a todos os sistemas complexos (Holling, 1973; Dalziell \& McManus, 2004; Rose \& Liao, 2005; 
Fiksel, 2006b; Hollnagel et al., 2006; Westrum, 2006; Arsenault \& Sood, 2007; van Opstal, 2007; Haimes et al., 2008; Gibbs 2009). No âmbito das ciências de gestão o conceito de resiliência organizacional fez a sua aparição no quadro das pesquisas sobre gestão de crises. A análise passou assim do nível individual ao nível organizacional e colectivo a propósito dos mecanismos que tornam o grupo mais vulnerável face às ruturas (Weick, 1993) e sobre a capacidade da empresa em absorver, responder e capitalizar as ondas de choque das mudanças do seu meio envolvente (Lengnick-Hall \& Beck, 2005, 2009). Para ser resiliente a organização deve conseguir extrair lições das dificuldades que teve que enfrentar de modo a sair fortalecida aprendendo à sua própria custa (Christianson et al., 2009) uma vez que saber tirar partido dos problemas significa reconhecer, e não ignorar, a contribuição destes para uma nova aprendizagem (Thorne, 2000).

\section{O modelo proposto}

Fig. 2: Modelo elaborado pelo autor.

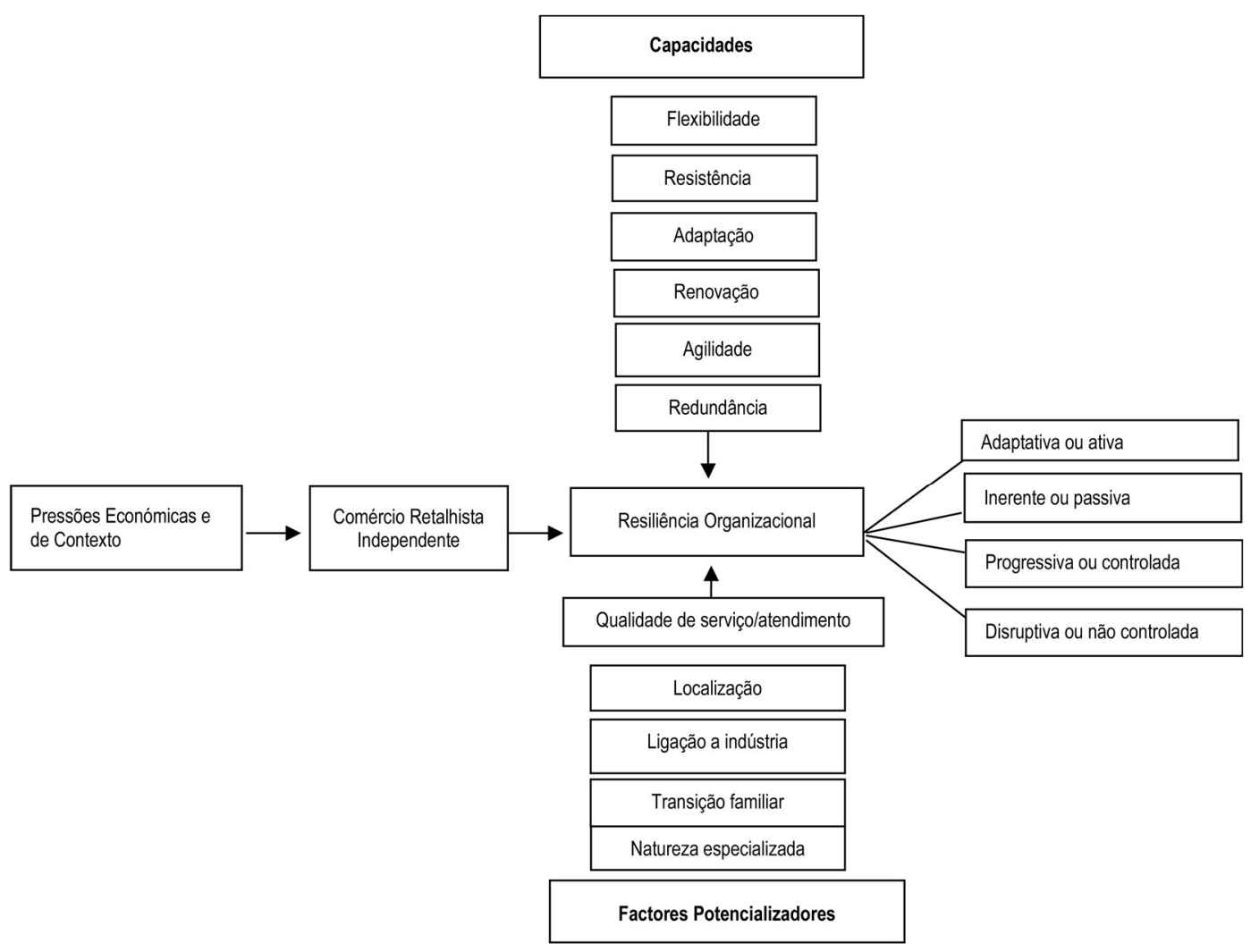

\section{Fundamentação das Hipóteses da parte qualitativa do estudo}

Uma hipótese é uma proposição provisória que carece de ser verificada ou como diz Kerlinger (1988) um enunciado conceptual das relações entre duas ou mais variáveis. Para Punch (1998) uma hipótese é uma previsão de resposta para o problema de investigação e expressa uma antecipação dos resultados. Em estudos qualitativos podem ser formuladas hipóteses indutivas que nascem das observações do investigador (Cardona Moltó, 2002). 
Nesta conformidade formulámos as seguintes quatro hipóteses indutivas que procuraremos validar:

$1^{\mathrm{a}} \mathrm{H}$ - As pressões económicas e de contexto contribuem para despoletar processos de resiliência do retalho independente.

$2^{\mathrm{a}} \mathrm{H}$ - A flexibilidade, a resistência, a renovação, a redundância, a agilidade e a adaptação são fatores constitutivos da resiliência dos formatos comerciais retalhistas independentes.

$3^{\mathrm{a}} \mathrm{H}$ - A transição familiar intergerações e a ligação da atividade retalhista a uma atividade industrial constituem-se como fatores potencializadores da resiliência dos formatos comerciais retalhistas independentes.

$4^{\mathrm{a}} \mathrm{H}$ - Os fatores internos tais como, a localização, a natureza ulta-especializada e a qualidade do serviço e do atendimento constituem-se como fatores potencializadores da resiliência do retalho independente.

\section{Caracterização da amostra}

Estamos perante uma amostra algo heterogénea que realça bem a diversidade dos negócios retalhistas que a compõem, mas também possuidora de um forte elemento de homogeneidade decorrente da sua localização, pois toda a amostra com a exceção da papelaria Fernandes, se encontra localizada na zona da cidade de Lisboa designada por Baixa/Chiado, facto que the confere uma incontestada e particular unidade. Por outro lado, destacam-se três grandes grupos de ramos de atividade comercial com particular destaque para as farmácias que constituem quase um quarto da amostra com dez pontos de venda logo seguidas das lojas de moda/desporto com 6 estabelecimentos e as retrosarias com quatro representantes. Estabelecimentos de alimentação e bebidas encontram-se quatro, ourivesarias três e com duas unidades temos jogo e lotarias, oculistas e lojas de malas, peles e marroquinaria. De todos os restantes ramos de atividade só consta uma unidade de cada.

\section{Resultados e Conclusões da parte qualitativa}

O modelo de resiliência organizacional do retalho independente elaborado e proposto (Fig. 2) foi validado $\mathrm{e}$ as hipóteses indutivas apresentadas foram efetivamente demonstradas. Todas as empresas da amostra perante a questão de saber que tipo de pressões sentiam no mercado em que competiam, evidenciaram uma nítida consciência de serem essas pressões relativas à conjuntura económica, às dos consumidores e às do mercado e da concorrência, as principais causas para desenvolverem as suas capacidades resilientes, sendo poucas vezes referidas as pressões políticas ou tecnológicas, exceto no caso da Casa Campião em que estes dois tipos de pressões, foram considerados os mais fortes tal como as restrições legais. Logo, podemos concluir que as pressões económicas e de contexto contribuem para despoletar processos de resiliência do retalho independente verificando-se assim a primeira hipótese formulada no estudo qualitativo e atingindo-se o primeiro objetivo pretendido. Constata-se como assinala Dawson, (1983), que estas empresas independentes de pequena dimensão estão, de uma forma geral, mal preparadas para lidar com as constantes mudanças das circunstâncias de mercado, facto que conduz a especulações sobre o seu desaparecimento fundadas sobre a sua crescente obsolescência em termos de ambiente negocial, formato retalhista e forma de gestão (Kirby, 1986). Daí 
que a reduzida dimensão destas organizações (e do seu negócio), apontado quase sempre como um sério constrangimento no sector do comércio a retalho, pode constituir-se como um fator decisivo para a necessária capacidade de adaptação, por via de uma maior flexibilidade para a introdução de mudanças (Barreta, 2013).

Quanto à questão de saber se qualidades como a flexibilidade, a resistência, a renovação, a redundância, a agilidade e a adaptação são fatores constitutivos da resiliência dos formatos comerciais retalhistas independentes, também, de um modo geral, foram referidas e assumidas pelas empresas da amostra, destacando-se entre elas, tal como atrás já evidenciámos, as capacidades da resistência, da redundância e da adaptação. Os resultados demonstram ainda que a reduzida dimensão das empresas retalhistas centenárias de Lisboa terá sido um dos fatores que lhes permitiu adquirir a necessária flexibilidade para se manterem no mercado.

De facto, muitos são os autores que têm evidenciado que essas empresas possuem uma grande flexibilidade na escolha de seus mercados-alvo e na adoção das suas estratégias (Berman \& Evans, 2014; Davies \& Harris, 1990; Conant \& White, 1999). A proximidade destas lojas com os clientes e alguma capacidade de responder rapidamente às constantes alterações de mercado permitiram-lhes manter um certo grau de competitividade e dar-lhes uma forte base de subsistência (Megicks, 2001). Fica igualmente demonstrado que dos fatores potencializadores da resiliência destas empresas retalhistas centenárias foi a localização dos seus pontos de venda - todos situados na baixa pombalina de Lisboa aquele que, quer pelo testemunho dos próprios comerciantes quer pela perceção dos consumidores de Lisboa, maior contributo terá tido na explicação da longevidade destes negócios ao longo de mais de um século, logo o seu principal fator de resiliência.

Da análise dos resultados verificamos por outro lado que a capacidade mais vezes nomeada e reconhecida como elemento constitutivo da resiliência foi a resistência, de imediato seguida pela redundância e, pela adaptação com 56\% de referências. Mas para a maior parte dos autores não é a resistência, mas antes a capacidade de adaptação o conceito mais frequentemente associado à resiliência (Goble et al., 2002; Dalziell \& McManus, 2004; Fiksel, 2006; Gallopin, 2006; Stevenson \& Spring, 2007; Gibbs, 2009) sendo esta definida como a flexibilidade para experimentar e adoptar novas soluções e desenvolvimento de respostas generalizadas para diferentes mudanças. O conceito de redundância é igualmente muito relacionado com resiliência e como sua fonte ou origem (Goble et al., 2002; Dalziell \& McManus, 2004; Sheffi \& Rice, 2005; Haimes et al., 2008; Hu et al., 2008) definindo estes autores redundância como a conservação de capacidades extra ou reserva de recursos que permitem produzir a resiliência. Fica demonstrado que a flexibilidade que se tornou num construto emergente da resiliência (Sheffi \& Rice, 2005; Stevenson \& Spring, 2007; Haimes et al., 2008) tendo alguns estudos sobre resiliência sugerido que a capacidade de adaptação de um sistema, em caso de disrupção, pode ser acrescida pela anterior planificação e introdução de flexibilidade no sistema (Carpenter et al., 2001; Walker et al., 2004; Sheffi \& Rice, 2005) e a agilidade que caracteriza a capacidade de resposta de um sistema face às rápidas mudanças ocorridas em ambientes incertos, foram as menos referidas pelas empresas da amostra. 
Estamos convencidos que os resultados obtidos nos permitem responder à questão principal desta investigação, ou seja, o que é que faz uma empresa ser considerada resiliente? Tal como McGee e Peterson (2000) que num estudo efetuado sobre a ligação substantiva entre os recursos das empresas e as suas vantagens competitivas, concluíram que o desempenho dos pequenos retalhistas independentes parecia estar positivamente correlacionado com uma imagem de alta qualidade de serviço e com capacidades de ação operacional e de controlo das suas políticas de preços também este estudo revela que fatores como a qualidade do serviço prestado e do atendimento e a natureza especializada do sortido foram particularmente referidos como potencializadores da resiliência organizacional do retalho independente.

Relativamente à questão de determinar se a transição familiar intergerações e a ligação da atividade retalhista a uma atividade industrial se constituíam como fatores potencializadores da resiliência dos formatos comerciais retalhistas independentes, as reduzidas percentagens de referências obtidas apenas nos permitem concluir que, embora também se verificando não são, contudo, determinantes, ou seja, mesmo não existindo essas empresas teriam conseguido atingir um grau elevado de longevidade. São, assim, os fatores com menor potencial de resiliência encontrados, facto que, em certa medida, face à perceção ainda existente, constitui uma surpresa deste estudo, particularmente no que se refere ao fator da transferência intergeracional. Por fim, no que concerne à intenção de determinar se os fatores internos da atividade comercial, tais como, a localização, a natureza ulta-especializada e a qualidade do serviço e do atendimento, se constituíam como fatores potencializadores da resiliência do retalho independente, pensamos que estes foram inequivocamente demonstrados e confirmados pelos resultados da pesquisa exploratória efetuada através da amostra de empresas estudada que, no fundo, representava o universo total de lojas centenárias de Lisboa.

\section{Modelo de análise e proposições de pesquisa da parte quantitativa do estudo}

Com o objetivo de estudar, na ótica dos consumidores, o problema central de investigação considerou-se necessário analisá-lo em 3 dimensões que, decompondo o problema central, nos permitirão investigar com mais detalhe e profundidade. Desta forma elaboraram-se as seguintes dimensões de investigação:

D1H1. O grau de preferência das lojas centenárias de Lisboa justificadora do seu grau de resiliência depende da existência de fatores estruturais e funcionais que essas lojas possuem.

D2H2. O grau de longevidade das lojas centenárias de Lisboa justificadora do seu grau de resiliência depende da existência de fatores estruturais e funcionais que essas lojas possuem. (P6)

A partir destas duas dimensões elaboraram-se para cada uma o mesmo conjunto de hipóteses para aferir a perceção dos consumidores quer ao grau de preferência (de D1H1a. a D1H1g.) quer ao grau de longevidade (de D2H1h. a D2H1o.) das lojas centenárias, em virtude de determinados fatores estruturais e funcionais que tais lojas possuem, nomeadamente as seguintes hipóteses de investigação: 
D1H1a./ D2H1h. A sua localização próxima é fator de preferência/longevidade D1H1b./ D2H1i. A sua fácil acessibilidade é fator de preferência/Longevidade D1H1c. /D2H1j. A sua natureza ultra especializada ou única dos produtos oferecidos é fator de preferência/Longevidade

D1H1d. /D2H1l. A manutenção do negócio dentro da mesma família ao longo de gerações é fator de preferência/Longevidade

H1e. $/ D 2 H 1 m$. A relação funcional existente entre o tipo de produtos oferecidos e o seu modo de produção é fator de preferência/Longevidade

DIH1f. ID2H1n. O conhecimento pessoal dos seus clientes associado à qualidade dos serviços prestados e do atendimento personalizado é fator de preferência/Longevidade

D1H1g. ID2H1o. A simplicidade, tradição, antiguidade e informalidade do negócio são fatores de preferência/Longevidade

As hipóteses das dimensões 1 e 2 foram encontradas durante a fase exploratória e qualitativa deste estudo resultando da seleção efetuada pelos proprietários/gestores das 47 lojas centenárias que constituíram a amostra da primeira fase deste estudo. A terceira dimensão do problema que pretendemos estudar irá permitir compreender quais as motivações dos consumidores quando decidem frequentar e comprar em lojas de retalho centenárias:

D3H3. O grau de preferência das lojas centenárias de Lisboa justificadora do seu grau de resiliência depende de motivações determinantes do comportamento dos consumidores. (P7).

A partir desta terceira dimensão construíram-se as seguintes hipóteses de investigação:

D3H3p: As motivações de compra dos consumidores estão relacionadas com as variáveis demográficas (Cox e Andersen, 2005; Jin \& Kim, 2003)

D3H3q: As motivações decorrentes da tipologia de loja oferecida aos consumidores (Mokhlis et al., 2003; Stoltman et al., 1991; Dawson et al., 1990)

D3H3r: Os atributos de conveniência estão relacionados com o tipo de procura em lojas centenárias independentes (Creusen \& Schoormans, 2005; Hassenzahl, Schöbel \& Trautmann, 2008; Voss, Spangenberg \& Grohmann, 2003)

D3H3s: A procura de preços baixos está relacionada com as razões de compra no retalho centenário (Collins et al., 2013)

D3H3t:O tipo de compra realizada é importante no processo de decisão (Bell, Corsten \& Knox, 2010; Hui, Inman, Huang \& Suther, 2013)

D3H3u: O tempo disponivel do consumidor durante o processo de compra no retalho centenário está relacionado com a sua eficiência na compra (Collins et al., 2013)

D3H3v: A procura de aventura e de entretenimento explica a motivação de compra nas lojas centenárias (Lachman \& Brett, 2013; Moutinho et al., 2010).

D3H3w: O grau de envolvimento do consumidor no processo da decisão de compra está relacionado com o nivel de satisfação obtido no retalho centenário (Ficke, 2014; Ryu et al., 2010) 
D3H3x: A motivação pela procura de novidades está relacionada com o processo de decisão de compra do consumidor no retalho centenário (Creusen \& Schoormans, 2005; Desmet \& Hekkert, 2007)

D3H3z: Os factores ambientais do ponto de venda estão relacionados com a decisão de compra do consumidor no retalho independente centenário (Ballantine, Jack \& Parsons, 2010; Hamrouni \& Touzi, 2011; Byun \& Mann, 2011)

Resume-se em seguida no Quadro 1, as hipóteses e sub-dimensões de investigação da terceira dimensão investigada pelo modelo conceptual.

Quadro 1 - Resumo das hipóteses de investigação.

\begin{tabular}{|c|c|}
\hline Hipótese de investigação & Sub-dimensão de pertença \\
\hline $\begin{array}{l}\text { H1: As variáveis demográficas influenciam as motivações de compra nas } \\
\text { lojas centenárias de Lisboa (P2D3H3p) }\end{array}$ & Variáveis demográficas \\
\hline $\begin{array}{l}\mathrm{H} 2 \text { : As motivações de compra dos consumidores estão relacionadas com a } \\
\text { sua escolha do tipo de loja retalhista }(\mathrm{P} 2 \mathrm{D} 3 \mathrm{H} 3 \mathrm{q})\end{array}$ & Escolha da loja retalhista \\
\hline $\begin{array}{l}\text { P3: Os atributos de conveniência estão relacionados com o tipo de procura } \\
\text { para a compra em lojas centenárias independentes (P2D3H3r) }\end{array}$ & Conveniência \\
\hline $\begin{array}{l}\text { P4: A procura de preços baixos está relacionada com as razões de compra no } \\
\text { retalho centenário }(\mathrm{P} 2 \mathrm{D} 3 \mathrm{H} 3 \mathrm{~s})\end{array}$ & Economia \\
\hline $\begin{array}{l}\text { P5: A procura objetiva de compra no retalho centenário está relacionada com } \\
\text { a sua realização de compra }(\mathrm{P} 2 \mathrm{D} 3 \mathrm{H} 3 \mathrm{t})\end{array}$ & Realização \\
\hline $\begin{array}{l}\text { P6: O tempo disponível do consumidor durante o processo de compra no } \\
\text { retalho centenário está relacionado com a sua eficiência na compra } \\
(\mathrm{P} 2 \mathrm{D} 3 \mathrm{H} 3 \mathrm{u})\end{array}$ & Eficiência \\
\hline $\begin{array}{l}\text { P7: A procura de aventura e de entretenimento explica a motivação de } \\
\text { compra nas lojas centenárias }(\mathrm{P} 2 \mathrm{D} 3 \mathrm{H} 3 \mathrm{v})\end{array}$ & Aventura / divertimento \\
\hline $\begin{array}{l}\text { P8: O grau de envolvimento do consumidor no processo da decisão de } \\
\text { compra está relacionado com o nível de satisfação obtido no retalho } \\
\text { centenário (P2D3H3w) }\end{array}$ & Satisfação \\
\hline $\begin{array}{l}\text { P9: A motivação pela procura de novidades está relacionada com o processo } \\
\text { de decisão de compra do consumidor no retalho centenário (P2D3H3x) }\end{array}$ & Procura de novidades \\
\hline $\begin{array}{l}\text { P10: Os fatores ambientais do ponto de venda estão relacionados com a } \\
\text { decisão de compra do consumidor no retalho independente centenário } \\
(\mathrm{P} 2 \mathrm{D} 3 \mathrm{H} 3 \mathrm{z})\end{array}$ & Ambiente da loja \\
\hline
\end{tabular}

A partir destas três dimensões e respetivas hipóteses de investigação desenhámos o seguinte modelo de investigação (Fig.3): 
Fig. 3 - Modelo de investigação dos fatores de preferência, de longevidade e de motivação dos consumidores perante as lojas centenárias.

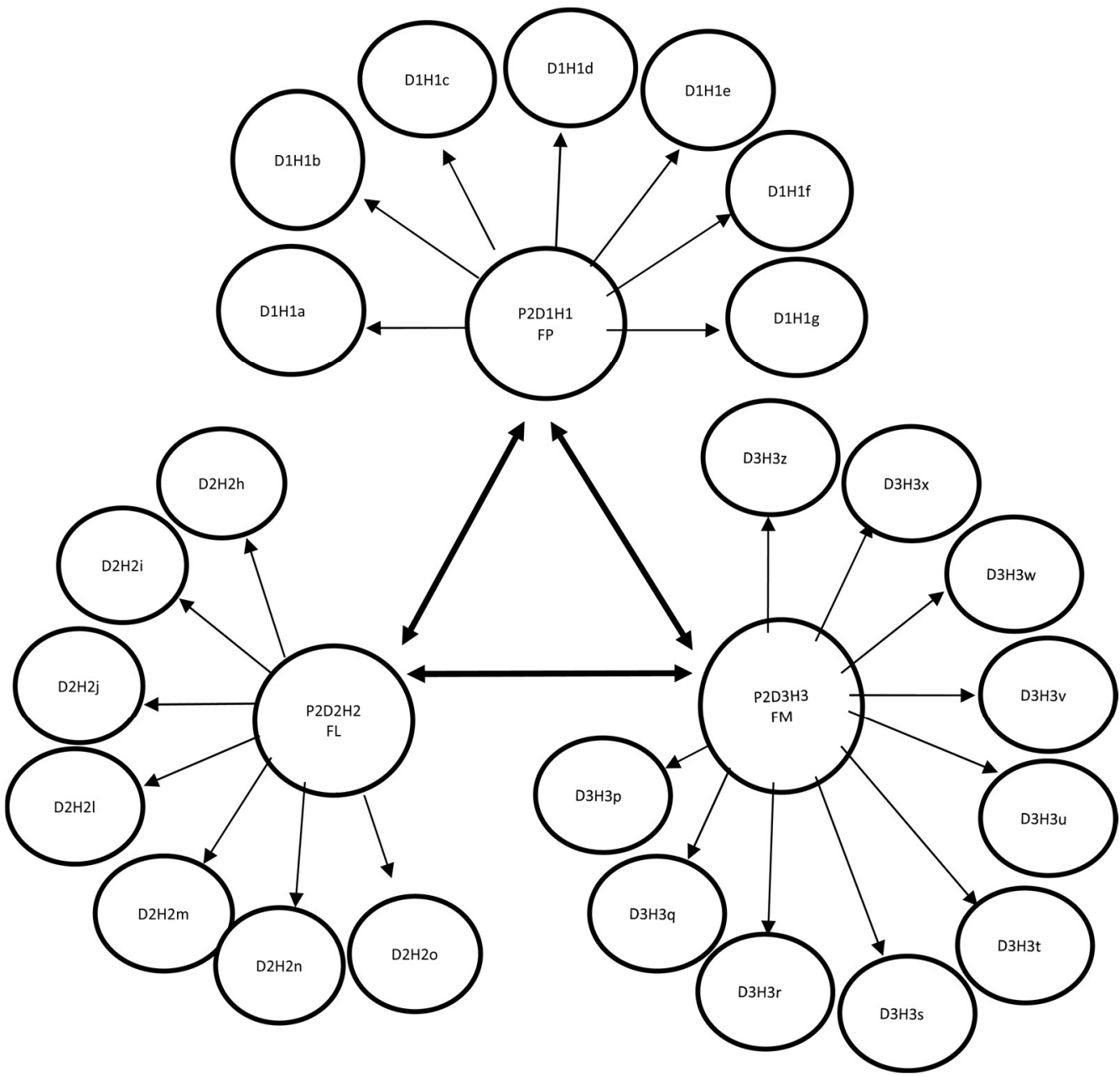

Análise dos resultados

As propriedades estatísticas dos dados recolhidos pela amostra $(n=472)$ são satisfatórias a nível univariado, quanto à independência e normalidade da distribuição (teste Saphiro-Wilk) e à homogeneidade da variância (homocedasticidade, teste de Lavene) bem como as restantes propriedades psicométricas dos itens da escala também não sugerem qualquer imparidade conforme tabela 6 elaborada segundo o critério descendente da média verificada.

Face à amostra bruta de 472 inquiridos constatam-se, no entanto, casos de dados ausentes (não resposta) por parte de 261 consumidores que alegaram desconhecer lojas retalhistas centenárias de Lisboa pelo que só foram consideradas na análise as respostas de 211 consumidores ou seja $44,7 \%$ dos inquiridos.

Como se pode verificar na referida tabela 1 a média mais elevada (M:4,34;d.p.0,772) corresponde à hipótese da simplicidade, tradição, antiguidade e informalidade do negócio (P2D2H2o) na dimensão longevidade de imediato seguida pela hipótese do conhecimento pessoal dos seus clientes associado à qualidade dos serviços prestados e do atendimento personalizado (P2D1H1f) na dimensão de preferência enquanto a média mais reduzida 
(M:3,12;d.p.1,140) corresponde à hipótese da facilidade de acesso (P2D2H2i) na dimensão longevidade.

$\mathrm{Na}$ dimensão dos fatores motivacionais a melhor média é obtida pelo nível de satisfação obtido no retalho centenário (P2D3H3w) com os valores de M:4,13; d.p.0,761.

Tabela 1 - Análise descritiva das hipóteses por hierarquia de médias obtidas.

\begin{tabular}{|c|c|c|c|c|c|c|}
\hline \multicolumn{7}{|c|}{ Descriptive Statistics } \\
\hline & $\mathrm{N}$ & Minimum & Maximum & Sum & Mean & $\begin{array}{c}\text { Std. } \\
\text { Deviation }\end{array}$ \\
\hline $\begin{array}{l}\text { P.6. - A simplicidade, tradição, antiguidade e informalidade } \\
\text { do negócio }\end{array}$ & 211 & 1 & 5 & 915 & 4,34 & ,772 \\
\hline $\begin{array}{l}\text { P.5. - O conhecimento pessoal dos seus clientes associado à } \\
\text { qualidade dos serviços prestados e do atendimento } \\
\text { personalizado }\end{array}$ & 211 & 1 & 5 & 893 & 4,23 & ,838 \\
\hline $\begin{array}{l}\text { P.6. - A manutenção do negócio dentro da mesma família ao } \\
\text { longo de gerações }\end{array}$ & 211 & 1 & 5 & 891 & 4,22 & ,858 \\
\hline P.6 A natureza ultra especializada dos seus produtos & 211 & 1 & 5 & 887 & 4,20 & ,868 \\
\hline P.5. - A natureza ultra especializada dos seus produtos & 211 & 1 & 5 & 885 & 4,19 & 796 \\
\hline $\begin{array}{l}\text { P.5. - A manutenção do negócio dentro da mesma família ao } \\
\text { longo de gerações }\end{array}$ & 211 & 1 & 5 & 883 & 4,18 & ,930 \\
\hline $\begin{array}{l}\text { P.6. - A relação funcional existente entre o tipo de produtos } \\
\text { oferecidos e o seu modo de produção }\end{array}$ & 211 & 1 & 5 & 873 & 4,14 & 790, \\
\hline $\begin{array}{l}\text { P.7. - Motivações decorrentes do nível de satisfação obtido } \\
\text { no retalho centenário }\end{array}$ & 211 & 1 & 5 & 871 & 4,13 & 761 \\
\hline $\begin{array}{l}\text { P.5. A relação funcional existente entre o tipo de produtos } \\
\text { oferecidos e o seu modo de produção }\end{array}$ & 211 & 1 & 5 & 851 & 4,03 & 765, \\
\hline $\begin{array}{l}\text { P.4. E em qual ou quais já teve oportunidade de fazer } \\
\text { compras? }\end{array}$ & 7 & 4 & 4 & 28 & 4,00 & 000, \\
\hline $\begin{array}{l}\text { P.3. Das lojas centenárias de Lisboa constantes da seguinte } \\
\text { lista, qual ou quais conhece ou já ouviu falar? }\end{array}$ & 39 & 4 & 4 & 156 & 4,00 & 000 \\
\hline $\begin{array}{l}\text { P.7. Motivações relacionadas com o tipo de loja oferecida aos } \\
\text { consumidores }\end{array}$ & 211 & 1 & 5 & 804 & 3,81 & 863, \\
\hline $\begin{array}{l}\text { P.7. Motivações decorrentes dos factores ambientais } \\
\text { existentes no ponto de venda }\end{array}$ & 211 & 1 & 5 & 798 & 3,78 & 926, \\
\hline $\begin{array}{l}\text { P.7. Motivações decorrentes de variáveis demográficas tais } \\
\text { como a idade, estado civil... }\end{array}$ & 211 & 1 & 5 & 751 & 3,56 & 905, \\
\hline $\begin{array}{l}\text { P.7. Motivações decorrentes do tempo disponível do } \\
\text { consumidor no seu processo de compra }\end{array}$ & 211 & 1 & 5 & 746 & 3,54 & 917, \\
\hline $\begin{array}{l}\text { P.7. Motivações relacionadas com a conveniência da compra } \\
\text { tais como os horários }\end{array}$ & 211 & 1 & 5 & 740 & 3,51 & 997, \\
\hline P.7. Motivações decorrentes dos baixos preços praticados & 211 & 1 & 5 & 737 & 3,49 & ,987 \\
\hline P.5. - A localização próxima & 211 & 1 & 5 & 736 & 3,49 & 1,044 \\
\hline P.7. Motivações relacionadas com a procura de novidades & 211 & 1 & 5 & 725 & 3,44 & ,931 \\
\hline P.6. - A localização próxima & 211 & 1 & 5 & 714 & 3,38 & 1,046 \\
\hline $\begin{array}{l}\text { P.7. - Motivações relacionadas com a realização da compra } \\
\text { planeada ou por impulso }\end{array}$ & 211 & 1 & 5 & 702 & 3,33 & ,982 \\
\hline P.5. - O fácil acesso (estacionamento, transportes) & 211 & 1 & 5 & 691 & 3,27 & 1,113 \\
\hline $\begin{array}{l}\text { P.7. - Motivações relacionadas com a procura de aventura e } \\
\text { de entretenimento }\end{array}$ & 211 & 1 & 5 & 677 & 3,21 & 978 \\
\hline P.6. - O fácil acesso (estacionamento, transportes) & 211 & 1 & 5 & 659 & 3,12 & 1,140 \\
\hline
\end{tabular}


No que concerne às duas primeiras dimensões estudadas (P2D1H1 e P2D2H2) relativas aos fatores de preferência e fatores explicativos da longevidade do retalho independente de Lisboa e contrariando de certa forma a opinião expressa pelos comerciantes inquiridos no estudo qualitativo antes efetuado, o fator localização não é considerado pelos consumidores como o mais relevante fator de preferência ainda que tenha tido $51,7 \%$ de referências expressas assim como o fator acessibilidade que com $60,7 \%$ de referências expressas também fica abaixo dos restantes fatores. E quanto à importância da localização e da acessibilidade como fatores explicativos da sua longevidade e ainda que tenham tido respetivamente 46,9 e $59,7 \%$ de referências, tais valores quando comparados com os outros ficam muito aquém uma vez que ambos ficam abaixo dos 4\% de média (Quadro 2) com, nomeadamente, M:3,49;d.p.1.044 (P5.1) e M:3,38;d.p.1,046 (P6.1) e M:3,27;d.p.1,113 (P5.2) e M:3,12;d.p.1,14 (P6.2).

Quadro 2 - Fatores de preferência e de razões de longevidade (perceção dos consumidores).

\begin{tabular}{|c|c|c|c|}
\hline P2D1H1/P2D2H2 & $\begin{array}{c}\text { Questionário } \\
\text { Factores de preferência (P5) e de } \\
\text { longevidade (P6) }\end{array}$ & Média/desvio & $\begin{array}{l}\text { Confirma/ } \\
\text { n.confirma }\end{array}$ \\
\hline Localização próxima & A localização próxima & $\begin{array}{l}\text { P5.1 - M:3,49; d.p.1.044 } \\
\text { P6.1 - M:3,38;d.p.1,046 }\end{array}$ & Confirma \\
\hline Fácil acessibilidade & $\begin{array}{l}\text { O fácil acesso (estacionamento, } \\
\text { transportes) }\end{array}$ & $\begin{array}{l}\text { P5.2 - M:3,27;d.p.1,113 } \\
\text { P6.2 - M:3,12;d.p.1,14 }\end{array}$ & Confirma \\
\hline $\begin{array}{l}\text { A natureza ultra especializada } \\
\text { ou única dos produtos } \\
\text { oferecidos }\end{array}$ & $\begin{array}{l}\text { A natureza ultra especializada dos } \\
\text { seus produtos }\end{array}$ & $\begin{array}{l}\text { P5.3 - M:4,19;d.p.0,796 } \\
\text { P6.3 - M:4,2;d.p.0,868 }\end{array}$ & Confirma \\
\hline $\begin{array}{l}\text { A manutenção do negócio } \\
\text { dentro da mesma família ao } \\
\text { longo de gerações }\end{array}$ & $\begin{array}{l}\text { A manutenção do negócio dentro } \\
\text { da mesma família ao longo de } \\
\text { gerações }\end{array}$ & $\begin{array}{l}\text { P5.4 - M:4,18d.p.0,930 } \\
\text { P6.4 - M:4,22;d.p.0,858 }\end{array}$ & Confirma \\
\hline $\begin{array}{l}\text { A relação funcional existente } \\
\text { entre o tipo de produtos } \\
\text { oferecidos e o seu modo de } \\
\text { produção }\end{array}$ & $\begin{array}{l}\text { A relação funcional existente } \\
\text { entre o tipo de produtos } \\
\text { oferecidos e o seu modo de } \\
\text { produção }\end{array}$ & $\begin{array}{l}P 5.5 \text { - M:4.03;d.p.0,765 } \\
\text { P6.5 - M:4,14;d.p.0,79 }\end{array}$ & Confirma \\
\hline $\begin{array}{l}\text { O conhecimento pessoal dos } \\
\text { seus clientes associado à } \\
\text { qualidade dos serviços } \\
\text { prestados e do atendimento } \\
\text { personalizado }\end{array}$ & $\begin{array}{l}\text { O conhecimento pessoal dos seus } \\
\text { clientes associado à qualidade } \\
\text { dos serviços prestados e do } \\
\text { atendimento personalizado }\end{array}$ & $\begin{array}{l}\text { P5.6 - M:4,23;d.p.0,838 } \\
\text { P6.6 - M:4,36;d.p.0,819 }\end{array}$ & Confirma \\
\hline $\begin{array}{l}\text { A simplicidade, tradição, } \\
\text { antiguidade e informalidade } \\
\text { do negócio }\end{array}$ & $\begin{array}{l}\text { A simplicidade, tradição, } \\
\text { antiguidade e informalidade do } \\
\text { negócio }\end{array}$ & $\begin{array}{l}\text { P5.7 - M:4,36;d.p.0,764 } \\
\text { P6.7 - M:4,34;d.p.0,772 }\end{array}$ & Confirma \\
\hline
\end{tabular}

Podemos assim enunciar desde já uma das primeiras e mais importantes conclusões deste estudo, ou seja, as lojas centenárias de Lisboa revestem a natureza de lojas de destino. Por outro lado, a natureza do sortido ultra especializado ou único destas lojas é muito apreciada pelos inquiridos $(82,9 \%)$ que consideram este fator também importante $(81,5 \%)$ 
e muito importante $(43,6 \%)$ para explicar a sua longevidade com valores de média acima dos 4\%, nomeadamente com M:4,19;d.p.0,796 (P5.3) e 4,2/,868 (P6.3). De igual modo, a transição intergeracional que mantém uma natureza familiar do negócio também se assume como muito apreciada $(79,2 \%)$ e considerada por $81 \%$ como uma fator importante e por $45 \%$ como um fator muito importante de resiliência tal como as médias igualmente o evidenciam M:4,18;d.p.0,93 (P5.4) e M:4,22;d.p.0,858 (P6.4). A relação funcional estabelecida entre o tipo de produtos oferecidos no sortido e o seu modo de produção, ou seja, a associação positiva dos produtos a modos de produção clássicos ou artesanais mereceu uma apreciação muito positiva por parte de $79,1 \%$ dos inquiridos que consideraram ainda ser este um fator importante de resiliência para $80,5 \%$ e muito importante para $35,5 \%$ destes inquiridos, facto que as médias obtidas também espelham com M:4.03;d.p.0,765 (P5.5) e M:4,14;d.p.0,79 (P6.6). De igual modo, o conhecimento pessoal do comerciante e dos clientes, associado à qualidade dos serviços prestados e ao atendimento personalizado constituem para $83,4 \%$ dos inquiridos um fator apreciado e destes $44,1 \%$ consideram-no mesmo muito apreciado. Como fator de resiliência $88,1 \%$ consideram-no importante e destes, 52,6\% consideram-no mesmo muito importante tal como o comprovam as médias obtidas com M:4,23;d.p.0,838 (P5.6) e M:4,36;d.p.0,819 (P6.6). Por fim, aspetos tão básicos como a simplicidade, tradição, antiguidade e informalidade do negócio é apreciada por $88,1 \%$ e muito apreciada por $50,2 \%$ destes inquiridos sendo ainda considerado um fator e resiliência importante para $86,7 \%$ e muito importante para 49,3 destes inquiridos a exemplo do verificado nas médias com M:4,36;d.p.0,764 (P5.7) e 4,34/,772 P6.7).

Entrando agora na terceira dimensão estudada (P2D3H3) na qual analisamos as motivações dos consumidores para efetuarem compras nas lojas centenárias (Quadro 3) constatamos que no que se refere às Motivações decorrentes de variáveis demográficas, tais como, a idade, estado civil, ocupação, rendimentos e educação, 46\% dos inquiridos consideram serem estas motivações indiferentes ou nada importantes e apenas $39,8 \%$ as consideram importantes e destes uma escassa percentagem de $14,2 \%$ as consideram muito importantes. De qualquer forma e ainda que com valores relativamente baixos de média, nomeadamente, M:3,56;d.p.0,905 (P7.1) esta hipótese é confirmada. 
Quadro 3 - Fatores motivacionais dos consumidores.

\begin{tabular}{|c|c|c|c|}
\hline P2D3H3 & $\begin{array}{c}\text { Questionário } \\
\text { Fatores Motivacionais (P7) }\end{array}$ & Média/desvio & $\begin{array}{l}\text { Confirma/ } \\
\text { n.confirma }\end{array}$ \\
\hline $\begin{array}{l}\text { As motivações de compra } \\
\text { dos consumidores estão } \\
\text { relacionadas com as } \\
\text { variáveis demográficas }\end{array}$ & $\begin{array}{l}\text { Motivações decorrentes de variáveis } \\
\text { demográficas tais como a idade, estado } \\
\text { civil, ocupação, rendimentos e } \\
\text { educação }\end{array}$ & P7.1 - M:3,56;d.p.0,905 & Confirma \\
\hline $\begin{array}{l}\text { A tipologia de loja oferecida } \\
\text { aos consumidores é } \\
\text { relevante na escolha dos } \\
\text { consumidores }\end{array}$ & $\begin{array}{l}\text { Motivações relacionadas com o tipo de } \\
\text { loja oferecida aos consumidores tais } \\
\text { como a sua dimensão, a acessibilidade } \\
\text { ou o sortido }\end{array}$ & P7.2 - M:3,81;d.p.0,863 & Confirma \\
\hline $\begin{array}{l}\text { Os atributos de } \\
\text { conveniência estão } \\
\text { relacionados com o tipo de } \\
\text { procura em lojas } \\
\text { centenárias independentes }\end{array}$ & $\begin{array}{l}\text { Motivações relacionadas com a } \\
\text { conveniência da compra tais como os } \\
\text { horários, facilidade de estacionamento } \\
\text { ou proximidade }\end{array}$ & P7.3 - M:3,51;d.p.0,997 & Confirma \\
\hline $\begin{array}{l}\text { A procura de preços baixos } \\
\text { está relacionada com as } \\
\text { razões de compra no } \\
\text { retalho centenário }\end{array}$ & $\begin{array}{l}\text { Motivações decorrentes dos baixos } \\
\text { preços praticados }\end{array}$ & P7.4 - M:3,49;d.p.0,987 & Confirma \\
\hline $\begin{array}{l}\text { O tipo de compra realizada } \\
\text { é importante no processo } \\
\text { de decisão }\end{array}$ & $\begin{array}{l}\text { Motivações relacionadas com a } \\
\text { realização da compra planeada ou por } \\
\text { impulso }\end{array}$ & P7.5 - M:3,33;d.p.0,982 & Confirma \\
\hline $\begin{array}{l}\text { O tempo disponível do } \\
\text { consumidor durante o } \\
\text { processo de compra no } \\
\text { retalho centenário está } \\
\text { relacionado com a sua } \\
\text { eficiência na compra } \\
\end{array}$ & $\begin{array}{l}\text { Motivações decorrentes do tempo } \\
\text { disponível do consumidor no seu } \\
\text { processo de compra }\end{array}$ & P7.6 - M:3,54;d.p.0,917 & Confirma \\
\hline $\begin{array}{l}\text { A procura de aventura e de } \\
\text { entretenimento explica a } \\
\text { motivação de compra nas } \\
\text { lojas centenárias }\end{array}$ & $\begin{array}{l}\text { Motivações relacionadas com a procura } \\
\text { de aventura e de entretenimento }\end{array}$ & P7.7 - M:3,21;d.p.0,978 & Confirma \\
\hline $\begin{array}{l}\text { O grau de envolvimento do } \\
\text { consumidor no processo da } \\
\text { decisão de compra está } \\
\text { relacionado com o nível de } \\
\text { satisfação obtido no retalho } \\
\text { centenário }\end{array}$ & $\begin{array}{l}\text { Motivações decorrentes do nível de } \\
\text { satisfação obtido no retalho centenário }\end{array}$ & P7.8 - M:4,13;d.p.0,761 & Confirma \\
\hline $\begin{array}{l}\text { A motivação pela procura } \\
\text { de novidades está } \\
\text { relacionada } \\
\text { com o processo de decisão } \\
\text { de compra do consumidor } \\
\text { no retalho centenário }\end{array}$ & $\begin{array}{l}\text { Motivações relacionadas com a procura } \\
\text { de novidades }\end{array}$ & P7.9 - M:3,44;d.p.0,931 & Confirma \\
\hline $\begin{array}{l}\text { Os fatores ambientais do } \\
\text { ponto de venda estão } \\
\text { relacionados com a decisão } \\
\text { de compra do consumidor } \\
\text { no retalho independente } \\
\text { centenário }\end{array}$ & $\begin{array}{l}\text { Motivações decorrentes dos fatores } \\
\text { ambientais existentes no ponto de } \\
\text { venda tais como a cor, odor, música, } \\
\text { luz, design e relações com os } \\
\text { empregados }\end{array}$ & P7.10- M:3,78;d.p.0,926 & Confirma \\
\hline
\end{tabular}

Se atentarmos nas Motivações relacionadas com o tipo de loja oferecida aos consumidores, tais, como a sua dimensão, acessibilidade ou sortido já encontramos valores mais elevados com $66.8 \%$ dos inquiridos a considerarem estas motivações importantes e muito importantes e, só para $27 \%$ estas motivações são indiferentes, ainda que a média seja interessante M:3,81;d.p.0,863 (P7.2). Entrando agora nas Motivações relacionadas com 
atributos de conveniência da compra, tais como, os horários, a facilidade de estacionamento ou a proximidade, as opiniões dos inquiridos dividem-se quase a meio com 50,7\% a considerarem serem motivações importantes ou muito importantes e 45,6\% a considerarem o oposto, daí que a média seja positiva mas baixa com o valor de M:3,51;d.p.0,997 (P7.3). Quando procurámos saber se a procura de preços baixos está relacionada com as razões de compra no retalho centenário, nomeadamente se existiriam Motivações de compra decorrentes dos baixos preços praticados por este tipo de comércio, constatámos que de facto para $49,8 \%$ dos inquiridos os preços baixos são um factor importante ou muito importante e só para uma minoria de $14,7 \%$ os preços baixos são pouco ou nada importantes. Acresce ainda que para $35,5 \%$ dos inquiridos os preços praticados pelo comércio centenário são indiferentes. A média é positiva M:3,49;d.p.0,987 (P7.4) e permite-nos concluir que existe uma divisão acentuada entre os inquiridos com cerca de metade destes a valorizarem pouco ou nada os preços praticados e outra metade a relevarem como importante nas suas motivações de compra no retalho centenário os preços praticados.

Por sua vez, quando pesquisámos se o tipo de compra realizada é importante no processo de decisão dos consumidores, nomeadamente, se existirão Motivações relacionadas com a natureza da compra planeada ou da compra por impulso, $36 \%$ dos inquiridos consideram estas motivações como indiferentes ainda que para $36,5 \%$ sejam motivações importantes. Ainda que confirmada esta hipótese a sua média não é muito significativa com M:3,33;d.p.0,982 (P7.5).Testando depois se o tempo disponível do consumidor durante o processo de compra no retalho centenário está relacionado com a sua eficiência na compra, ou seja, se existirão Motivações decorrentes do tempo disponível do consumidor no seu processo de compra no retalho centenário, constatámos que a disponibilidade de tempo é indiferente para cerca de 34,6\% dos inquiridos ainda que de forma surpreendente $41,7 \%$ considerem o tempo uma motivação importante e 12,8\% uma motivação muito importante e uma escassa percentagem de 10,9\% considerem que o tempo é pouco ou nada importante. Ainda que confirmada também esta hipótese com o valor médio de M:3,54;d.p.0,917 (P7.6), penso que poderemos concluir que também o tempo disponível para fazer compras no comércio centenário começa a assumir alguma relevância nas motivações dos consumidores. E será que existirão importantes Motivações de compra relacionadas com a procura de aventura e de entretenimento no comércio centenário? De facto, teremos de concluir que não, na medida em que a maioria dos inquiridos $(60,7 \%)$ as considera indiferentes e pouco ou nada importantes. Com alguma surpresa cerca de um terço dos inquiridos $(33,2 \%)$ considera serem estas motivações importantes facto que permite ter uma média positiva ainda que das mais baixas com o valor de M:3,21;d.p.0,978 (P7.7).

Procurámos depois saber se o grau de envolvimento do consumidor no processo da decisão de compra está relacionado com o nível de satisfação obtido no retalho centenário e se existiriam motivações decorrentes desse facto e na verdade $82 \%$ dos inquiridos consideram importante e muito importante o nível de satisfação dos consumidores como uma das principais motivações de compra no comércio centenário, pelo que tal resultado se espelha na média de M:4,13;d.p.0,761 (P7.8), uma das mais elevadas verificadas neste 
estudo. Sendo, a procura de novidades, uma das mais importantes motivações dos consumidores nas suas decisões de compra, na maioria dos conceitos comerciais, quisemos determinar se tal facto se verificaria também no retalho centenário. Na realidade não o é para uma maioria de 50,7\% que considera ser este tipo de motivações indiferente ou pouco importante ainda que $40,3 \%$ as tenham considerado importantes ou muito importantes. Assim e ainda que positiva a sua média ficou-se pelos M:3,44;d.p.0,931 (P.7.9).

Por fim, fomos validar a hipótese de saber se os fatores ambientais do ponto de venda estão relacionados com a decisão de compra do consumidor no retalho independente centenário, isto é, se haverá Motivações decorrentes dos fatores ambientais existentes nos pontos de venda centenários, tais como, a cor, odor, música, luz, design e o relacionamento com os empregados. De facto, para $63,5 \%$ dos inquiridos os fatores ambientais motivamnos para fazer compras nas lojas centenárias ainda que para cerca de um terço $(30,3)$ tais motivações sejam indiferentes e para $6,2 \%$ pouco ou nada importantes. Verificou-se também nesta hipótese tal como todas as restantes confirmadas, uma média positiva de M:3,78; d.p.0,926 (P7.10).

\section{Validação dos dados}

De um modo geral, não se encontram correlações positivas fortes superiores a 0,8 sendo na sua grande maioria correlações positivas moderadas (compreendidas entre 0,5 e 0,8 ) e positivas fracas (compreendidas entre 0,1 e 0,5 ), Porém, e com raras exceções, o seu grau de significância foi de, 000 facto que nos permite concluir que a probabilidade de serem falsas é baixa ou nula. O valor do Alfa de Cronbach é superior a 0,80, (Tabela 2) e o teste ANOVA (Tabela 3) significativo que permite considerar uma excelente confiabilidade da escala, ou seja, as variáveis utilizadas medem de forma adequada as dimensões em causa não existindo itens correlacionados de forma negativa com a escala.

Tabela 2 - Teste geral de confiabilidade Alpha de Cronbach.

Reliability Statistics

\begin{tabular}{|c|c|c|}
\hline Cronbach's Alpha & Cronbach's Alpha Based on Standardized Items & $\mathrm{N}$ of Items \\
\hline ,905 & ,909 & 24 \\
\hline
\end{tabular}

Tabela 3 - Teste geral de confiabilidade ANOVA.

ANOVA

\begin{tabular}{|l|l|r|r|r|r|r|}
\hline \multicolumn{2}{|l|}{} & Sum of Squares & df & Mean Square & F & Sig \\
\hline \multicolumn{2}{|l|}{ Between People } & 1325,685 & 210 & 6,313 & & \\
\hline \multirow{3}{*}{ Within People } & Retween Items & 853,857 & 23 & 37,124 & 62,078 &, 000 \\
\cline { 2 - 7 } & Residual & 2888,476 & 4830 &, 598 & & \\
\cline { 2 - 7 } & Total & 3742,333 & 4853 &, 771 & & \\
\hline \multirow{2}{*}{ Total } & 5068,018 & 5063 & 1,001 & & \\
\hline
\end{tabular}


Para aprofundar a análise procedeu-se à transformação (agregação por escala sumativa) das variáveis da escala em três variáveis artificiais (construtos); ou seja, de acordo com os fatores (dimensões) de perceção dos consumidores para a escolha das lojas tradicionais: (a) fatores preferenciais; (b) fatores de longevidade; e (c) fatores motivacionais, conforme Tabela 4.

Tabela 4 - Caracterização dos constructos de perceção das preferências dos consumidores.

\begin{tabular}{|l|r|r|r|}
\hline & Descriptive Statistics & $\mathrm{N}$ \\
\hline Factores Preferenciais & Mean & Std. Deviation & 211 \\
Factores Longevidade & 3,9668 &, 60188 & 211 \\
Factores Motivacionais & 3,9675 &, 59876 & 211 \\
\hline
\end{tabular}

Efetuada uma análise da correlação de Pearson destas variáveis, constata-se que todas as correlações são significativas, moderadas e de sentido positivo entre si; sendo a correlação mais forte entre os Fatores Longevidade e Preferenciais, conforme tabela 5.

Tabela 5 - Correlação entre os construtos de perceção da preferência dos consumidores.

\begin{tabular}{|c|c|c|c|c|}
\hline \multicolumn{5}{|c|}{ Correlations } \\
\hline & & $\begin{array}{c}\text { Factores } \\
\text { Preferenciais }\end{array}$ & $\begin{array}{c}\text { Factores } \\
\text { Longevidade }\end{array}$ & Factores Motivacionais \\
\hline Fatores Preferenciais & $\begin{array}{l}\text { Pearson Correlation } \\
\text { Sig. (2-tailed) } \\
\text { N }\end{array}$ & $\begin{array}{r}1 \\
211\end{array}$ & $\begin{array}{r}, 729^{* *} \\
, 000 \\
211\end{array}$ & $\begin{array}{l}, 611^{* *} \\
, 000 \\
211\end{array}$ \\
\hline Fatores Longevidade & $\begin{array}{l}\text { Pearson Correlation } \\
\text { Sig. (2-tailed) } \\
\text { N }\end{array}$ & $\begin{array}{r}, 729^{* *} \\
, 000 \\
211\end{array}$ & $\begin{array}{r}1 \\
211\end{array}$ & $\begin{array}{l}, 527^{* *} \\
, 000 \\
211\end{array}$ \\
\hline Fatores Motivacionais & $\begin{array}{l}\text { Pearson Correlation } \\
\text { Sig. (2-tailed) } \\
\text { N }\end{array}$ & $\begin{array}{r}, 611^{* *} \\
, 000 \\
211\end{array}$ & $\begin{array}{r}, 527^{* *} \\
, 000 \\
211\end{array}$ & $\begin{array}{c}1 \\
211\end{array}$ \\
\hline
\end{tabular}

**. Correlation is significant at the 0.01 level (2-tailed).

Estas novas variáveis agregadas foram submetidas ao teste de confiabilidade do alfa de Cronbach (Tabela 6) que apresenta valores de superiores a 0,80 pelo que os construtos devem ser considerados válidos. 
Tabela 6 - Teste de confiabilidade dos constructos de perceção da preferência dos consumidores.

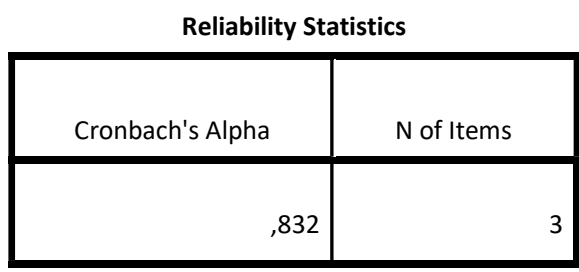

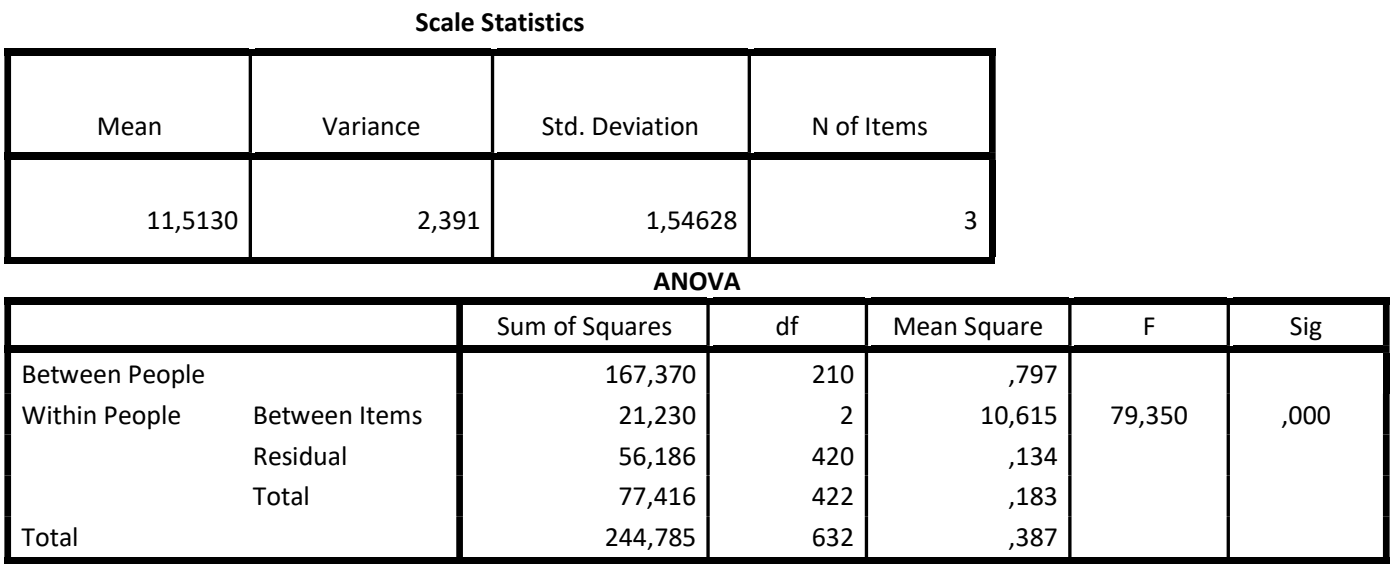

Grand Mean = 3,8377

Perante estes resultados, o constructo "Factores Motivacionais" foi constituído como variável dependente (VD) a explicar; e os constructos "Fatores Preferenciais" e "Fatores de Longevidade" como variáveis independentes (VI1, VI2) explicativas ou predictoras, para se proceder à determinação da explicação da variabilidade da motivação dos consumidores para escolher frequentar as lojas tradicionais. Este cálculo foi efetuado por uma análise RLM (regressão linear múltipla), pelo método stepwise, que oferece um teste mais rigoroso sobre os efeitos numa variável dependente de um conjunto de variáveis independentes. A regressão foi efetuada de acordo com a seguinte equação: VD (fatores motivacionais) $=k+$ VII (fatores de longevidade) + V2I(factores Preferênciais)

A variância total explicada pelo modelo de regressão é de 38,1\% (AjRSquare: 0,381) o que confirma uma parcial explicação da variabilidade dos "fatores motivacionais" pelos outros aspetos percetivos (preferência e longevidade) incluídos no modelo, conforme Tabela 7. 
Tabela 7 - Modelo de Regressão para Fatores Motivacionais.

Descriptive Statistics

\begin{tabular}{|l|r|r|r|}
\hline & Mean & $\begin{array}{c}\text { Std. } \\
\text { Deviation }\end{array}$ & N \\
\hline Factores Motivacionais & 3,5787 &, 58633 & 211 \\
Factores Preferenciais & 3,9668 &, 60188 & 211 \\
\hline
\end{tabular}

Model Summary

\begin{tabular}{|c|c|c|c|c|c|c|c|c|c|}
\hline \multirow{2}{*}{ Model } & \multirow[b]{2}{*}{$\mathrm{R}$} & \multirow{2}{*}{ R Square } & \multirow{2}{*}{$\begin{array}{l}\text { Adjusted R } \\
\text { Square }\end{array}$} & \multirow{2}{*}{$\begin{array}{l}\text { Std. Error of } \\
\text { the Estimate }\end{array}$} & \multicolumn{5}{|c|}{ Change Statistics } \\
\hline & & & & & $\begin{array}{l}\text { R Square } \\
\text { Change }\end{array}$ & F Change & df1 & $\mathrm{df} 2$ & $\begin{array}{c}\text { Sig. F } \\
\text { Change }\end{array}$ \\
\hline 1 &, $611^{a}$ & 0,373 & 0,37 & 0,46545 & 0,373 & 124,244 & 1 & 209 & 0 \\
\hline 2 &, $622^{b}$ & 0,387 & 0,381 & 0,46129 & 0,014 & 4,786 & 1 & 208 & 0,03 \\
\hline
\end{tabular}

a. Predictors: (Constant), Factores Preferenciais

b. Predictors: (Constant), Factores Preferenciais, Fatores Longevidade

c. Dependent Variable: Factores Motivacionais

ANOVAa

\begin{tabular}{|c|c|c|c|c|c|}
\hline Model & $\begin{array}{l}\text { Sum of } \\
\text { Squares }\end{array}$ & $\mathrm{df}$ & Mean Square & $\mathrm{F}$ & Sig. \\
\hline 1 Regression & 26,916 & 1 & 26,916 & 124,244 &, $000^{b}$ \\
\hline Residual & 45,278 & 209 & 217 & & \\
\hline Total & 72,194 & 210 & & & \\
\hline 2 Regression & 27,935 & 2 & 13,967 & 65,641 &, $000^{c}$ \\
\hline Residual & 44,259 & 208 & 213 & & \\
\hline Total & 72,194 & 210 & & & \\
\hline
\end{tabular}

a. Dependent Variable: Factores Motivacionais

b. Predictors: (Constant), Factores Preferenciais

c. Predictors: (Constant), Fatores Preferenciais, Fatores Longevidade 
A análise é significativa $(\mathrm{F}=65,641 ; \mathrm{sig}=0,000)$ e demonstra que os coeficientes de determinação significativos das variáveis explicativas são unicamente os do constructo "Fatores Preferenciais" (Beta Stand= 0,484; $\mathrm{t}=6,098 ; \mathrm{Sig}=0,000$ ). A variável independente explicativa não é estatisticamente significativa (Beta $\mathrm{Stand}=0,174 ; \mathrm{t}=2,188 ; \mathrm{Sig}=0,030$ ), conforme Tabela 8 .

Tabela 8 - Coeficientes de Regressão.

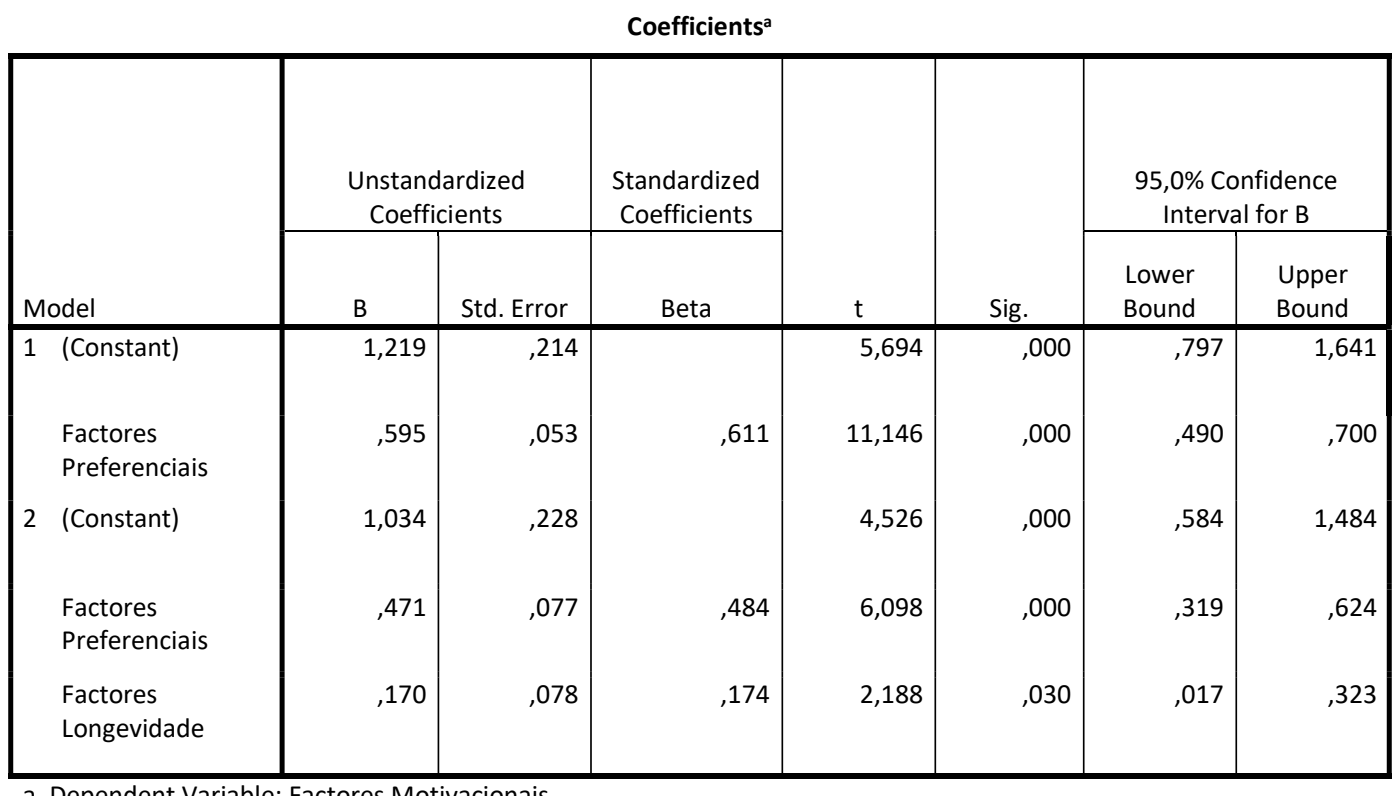

a. Dependent Variable: Factores Motivacionais

A equação de regressão obtida é a seguinte: VD (fatores motivacionais) 3,5787= $1,219+0,484 *$ (Fatores Preferenciais)

Ficando demonstrado que a motivação dos consumidores para frequentarem as lojas independentes centenárias depende significativamente e, em elevada e predominante medida, da sua perceção de preferências (localização, relação funcional do produto, etc) que constituem o construto Fatores Preferenciais e não sendo significativo, tal como se supunha inicialmente, a dependência dos aspetos de Longevidade. Para determinar com maior exatidão quais dos Fatores Preferenciais explicam a variabilidade da Motivação (Fatores Motivacionais) dos consumidores para utilizarem as lojas tradicionais procedeuse a uma segunda análise de regressão (RLM, pelo método stepwise).

Segundo a seguinte equação de regressão:

$V D$ (fatores motivacionais) $=k+V I 1$ (localização) + VI2(fácil acesso) +

VI3(especialização produtos) +VI4(negócio famíliar) + VI5 (relação funcional produto /produção) + VI6 (conhecimento e atendimento pessoal) + VI7(simplicidade, tradição, antiguidade e informalidade).

A análise é significativa ( $\mathrm{F}=33,562 ;$ sig $=0,000)$ e o modelo explica $38,3 \%$ da variância total (AjRSquare: 0,3831) dos "Fatores Motivacionais", conforme Tabela 9. 
Tabela 9 - Modelo de Regressão para a motivação dos consumidores.

\begin{tabular}{|c|c|c|c|c|c|c|c|c|c|}
\hline \multicolumn{10}{|c|}{ Model Summarye } \\
\hline \multirow[b]{2}{*}{ Model } & \multirow[b]{2}{*}{$\mathrm{R}$} & \multirow[b]{2}{*}{$\mathrm{R}$ Square } & \multirow[b]{2}{*}{$\begin{array}{l}\text { Adjusted } \\
\text { R Square }\end{array}$} & \multirow{2}{*}{$\begin{array}{l}\text { Std. } \\
\text { Error of } \\
\text { the } \\
\text { Estimate }\end{array}$} & \multicolumn{5}{|c|}{ Change Statistics } \\
\hline & & & & & $\begin{array}{l}\text { R Square } \\
\text { Change }\end{array}$ & $\begin{array}{c}\mathrm{F} \\
\text { Change }\end{array}$ & df1 & df2 & $\begin{array}{l}\text { Sig. F } \\
\text { Change }\end{array}$ \\
\hline 1 &, $538^{a}$ & ,290 & ,287 & ,49524 & ,290 & 85,357 & 1 & 209 &, 000 \\
\hline 2 &, $608^{b}$ & 369 & 363 & 46794 & 079 & 26,097 & 1 & 208 & 000 \\
\hline 3 & ,618 & ,382 & 373 & 46411 & 013 & 4,444 & 1 & 207 & ,036 \\
\hline 4 &, $628^{\mathrm{d}}$ & 395 & 383 & ,46063 & 012 & 4,140 & 1 & 206 & , 043 \\
\hline
\end{tabular}

a. Predictors: (Constant), P.5. Enquanto consumidor, qual ou quais dos seguintes fatores mais aprecia nestas lojas? - A localização próxima

b. Predictors: (Constant), P.5. Enquanto consumidor, qual ou quais dos seguintes fatores mais aprecia nestas lojas? - A localização próxima, P.5. Enquanto consumidor, qual ou quais dos seguintes fatores mais aprecia nestas lojas? - A relação funcional existente entre o tipo de produtos oferecidos e o seu modo de produção

c. Predictors: (Constant), P.5. Enquanto consumidor, qual ou quais dos seguintes fatores mais aprecia nestas lojas? - A localização próxima, P.5. Enquanto consumidor, qual ou quais dos seguintes fatores mais aprecia nestas lojas? - A relação funcional existente entre o tipo de produtos oferecidos e o seu modo de produção, P.5. Enquanto consumidor, qual ou quais dos seguintes fatores mais aprecia nestas lojas? - A natureza ultra especializada dos seus produtos

d. Predictors: (Constant), P.5. Enquanto consumidor, qual ou quais dos seguintes fatores mais aprecia nestas lojas? - A localização próxima, P.5. Enquanto consumidor, qual ou quais dos seguintes fatores mais aprecia nestas lojas? - A relação funcional existente entre o tipo de produtos oferecidos e o seu modo de produção, P.5. Enquanto consumidor, qual ou quais dos seguintes fatores mais aprecia nestas lojas? - A natureza ultra especializada dos seus produtos, P.5. Enquanto consumidor, qual ou quais dos seguintes fatores mais aprecia nestas lojas? - O fácil acesso (estacionamento, transportes)

e. Dependent Variable: Factores Motivacionais

ANOVA $^{\mathrm{a}}$

\begin{tabular}{|l|r|r|r|r|r|}
\hline Model & $\begin{array}{c}\text { Sum of } \\
\text { Squares }\end{array}$ & df & $\begin{array}{c}\text { Mean } \\
\text { Square }\end{array}$ & F & Sig. \\
\hline 4 Regression & 28,485 & 4 & 7,121 & 33,562 &, $000^{\circ}$ \\
Residual & 43,709 & 206 &, 212 & & \\
Total & 72,194 & 210 & & & \\
\hline
\end{tabular}

A análise conforme a Tabela 10 demonstra que os coeficientes de determinação mais significativos das variáveis explicativas são: "localização próxima" (Beta stand 0,332; $\mathrm{t}=4,559$; sig=0,000) e "relação funcional" (Beta stand 0,251; $\mathrm{t}=3,956$; sig=0,000). 
Tabela 10 - Coeficientes de Regressão mais significativos.

\begin{tabular}{|c|c|c|c|c|c|c|c|}
\hline \multicolumn{8}{|l|}{ Coefficients $^{\mathrm{a}}$} \\
\hline \multirow[b]{2}{*}{ Model } & \multicolumn{2}{|c|}{$\begin{array}{l}\text { Unstandardized } \\
\text { Coefficients }\end{array}$} & \multirow{2}{*}{\begin{tabular}{|c}
$\begin{array}{c}\text { Standardized } \\
\text { Coefficients }\end{array}$ \\
Beta \\
\end{tabular}} & \multirow[b]{2}{*}{$\mathrm{t}$} & \multirow[b]{2}{*}{ Sig. } & \multicolumn{2}{|c|}{$\begin{array}{l}95,0 \% \text { Confidence } \\
\text { Interval for B }\end{array}$} \\
\hline & B & Std. Error & & & & $\begin{array}{l}\text { Lower } \\
\text { Bound }\end{array}$ & $\begin{array}{l}\text { Upper } \\
\text { Bound }\end{array}$ \\
\hline 4 (Constant) & 1,513 & ,206 & & 7,333 & ,000 & 1,106 & 1,919 \\
\hline $\begin{array}{l}\text { P.5. Enquanto } \\
\text { consumidor, qual ou } \\
\text { quais dos seguintes } \\
\text { fatores mais aprecia } \\
\text { nestas lojas? - A } \\
\text { localização próxima }\end{array}$ & 187 & 041 & ,332 & 4,559 &, 000 & ,106 & ,267 \\
\hline $\begin{array}{l}\text { P.5. Enquanto } \\
\text { consumidor, qual ou } \\
\text { quais dos seguintes } \\
\text { fatores mais aprecia } \\
\text { nestas lojas? - A relação } \\
\text { funcional existente } \\
\text { entre o tipo de } \\
\text { produtos oferecidos e o } \\
\text { seu modo de produção }\end{array}$ & 193 & , 049 & ,251 & 3,956 &, 000 & ,097 & ,288 \\
\hline $\begin{array}{l}\text { P.5. Enquanto } \\
\text { consumidor, qual ou } \\
\text { quais dos seguintes } \\
\text { fatores mais aprecia } \\
\text { nestas lojas? - A } \\
\text { natureza ultra } \\
\text { especializada dos seus } \\
\text { produtos }\end{array}$ & ,094 & ,046 & 128 & 2,067 & ,040 & ,004 & 184 \\
\hline $\begin{array}{l}\text { P.5. Enquanto } \\
\text { consumidor, qual ou } \\
\text { quais dos seguintes } \\
\text { fatores mais aprecia } \\
\text { nestas lojas? - O fácil } \\
\text { acesso } \\
\text { (estacionamento, } \\
\text { transportes) }\end{array}$ & 074 & 037 & 141 & 2,035 & ,043 & ,002 & 146 \\
\hline
\end{tabular}

Fica demonstrado que a variabilidade da motivação é de forma significativa dependente, da localização e da relação produto e respetivo sistema de produção. Tendo sido identificadas as duas variáveis mais significativas na variação das motivações de compra dos consumidores para o retalho independente centenário - a localização próxima e a relação funcional existente entre o tipo de produtos oferecidos e o seu modo de produção - foi-se verificar a associação destas variáveis com as variáveis de perfil (sexo, idade e nível de instrução) dos consumidores, conforme Tabela 11. Desta análise constata-se que as mulheres ainda que ligeiramente valorizam mais o fator localização e o fator da relação existente entre o tipo de produtos oferecidos e o seu modo de produção que os homens.

Curiosamente, constata-se também que o fator localização é mais relevante para os consumidores da faixa etária 35 a 45 anos o mesmo acontecendo para o fator da relação 
existente entre o tipo de produtos oferecidos e o seu modo de produção. Quanto ao nível de instrução constata-se que os consumidores de formação superior são os que mais valorizam relação existente entre o tipo de produtos oferecidos e o seu modo de produção não sendo importante o fator localização.

Tabela 11 - Ventilações das Variáveis Demográficas dos Fatores determinantes da Motivação do Consumidor.

Case Processing Summary

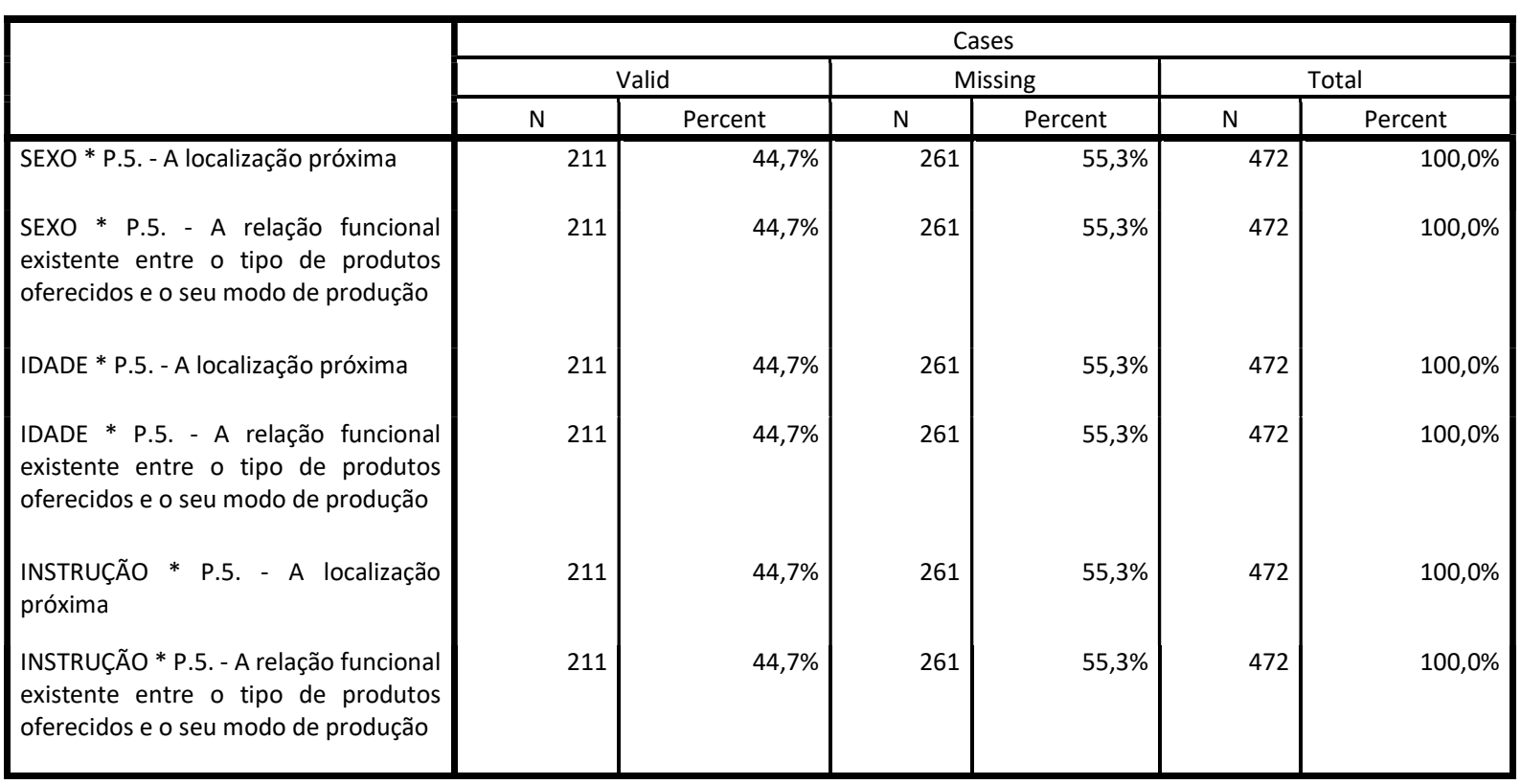

\section{Discussão}

A parte quantitativa deste estudo valida de forma inequívoca, e em qualquer das dimensões estudadas, os fatores localização e acessibilidade como fatores de grande importância na preferência dos consumidores pelas lojas centenárias confirmando-se todas as hipóteses formuladas no estudo quantitativo. A relação funcional estabelecida entre o tipo de produtos oferecidos no sortido e o seu modo de produção, ou seja, a associação positiva dos produtos a modos de produção clássicos ou artesanais mereceu uma apreciação muito positiva por parte dos inquiridos que consideraram ainda ser este um fator importante de resiliência ou muito importante. De igual modo, o conhecimento pessoal do comerciante e dos clientes, associado à qualidade dos serviços prestados e ao atendimento personalizado constituem-se um fator apreciado ou mesmo muito apreciado e como fator de resiliência também foi considerado importante ou mesmo muito importante. Por fim, aspetos tão básicos como a simplicidade, tradição, antiguidade e informalidade do negócio foram bastante apreciados pelos consumidores inquiridos sendo ainda considerado um fator de resiliência importante ou muito importante. 
No que concerne à terceira dimensão estudada (P2D3H3) na qual analisámos as motivações dos consumidores para efetuarem compras nas lojas centenárias, esta investigação confirma igualmente todas as hipóteses formuladas. Contudo, fica demonstrado que as variáveis demográficas, tais como, a idade, estado civil, ocupação, rendimentos e educação, não são das mais relevantes tal como as motivações relacionadas com o tipo de loja oferecida aos consumidores, nomeadamente, a sua dimensão, acessibilidade ou sortido oferecido e ainda as motivações relacionadas com atributos de conveniência da compra, tais como, os horários, a facilidade de estacionamento ou a proximidade. Quando procurámos saber se a procura de preços baixos está relacionada com as razões de compra no retalho centenário, nomeadamente se existiriam motivações de compra decorrentes dos baixos preços praticados por este tipo de comércio, os resultados obtidos permitem-nos concluir que existe uma divisão acentuada entre os consumidores com cerca de metade destes a valorizarem pouco ou nada os preços praticados e outra metade a relevarem como importante nas suas motivações de compra no retalho centenário os preços praticados. Por sua vez, quando pesquisámos se o tipo de compra realizada é importante no processo de decisão dos consumidores, nomeadamente, se existirão motivações relacionadas com a natureza da compra planeada ou da compra por impulso e ainda que confirmada esta hipótese a sua média não é muito significativa (M:3,33; d.p.0,982), facto que nos permite concluir que a tipologia de compra não é verdadeiramente importante para os consumidores quando fazem compras em lojas centenárias. Testando depois se o tempo disponível do consumidor durante o processo de compra no retalho centenário está relacionado com a sua eficiência na compra, ou seja, se existirão motivações decorrentes do tempo disponível do consumidor no seu processo de compra no retalho centenário, concluímos que também o tempo disponível para fazer compras no comércio centenário começa a assumir alguma relevância nas motivações dos consumidores. Fica também revelado neste estudo que as motivações de compra relacionadas com a procura de aventura e de entretenimento no comércio centenário não são relevantes ainda que cerca de um terço dos inquiridos as tenham considerado motivações importantes. Quanto ao grau de envolvimento do consumidor no processo da decisão de compra estar relacionado com o nível de satisfação obtido no retalho centenário os resultados obtidos demonstram, sem qualquer dúvida, ser esta uma das mais importantes motivações de compra no comércio centenário ao invés da procura de novidades, (uma das mais importantes motivações dos consumidores nas suas decisões de compra na maioria dos outros conceitos comerciais) que, na realidade não o é para a maioria dos consumidores no caso das lojas centenárias. A última das hipóteses confirmada tinha a ver com os fatores ambientais do ponto de venda e a sua relação com a decisão de compra do consumidor no retalho independente centenário, isto é, se haveria motivações decorrentes dos fatores ambientais existentes nos pontos de venda centenários, tais como, a cor, odor, música, luz, design e o relacionamento com os empregados, ficando por demais validado, serem estes fatores realmente importantes como motivação de compra no retalho centenário. 


\section{Conclusões}

Este estudo demonstra que a motivação dos consumidores para frequentarem as lojas independentes centenárias depende significativamente e, em elevada e predominante medida, da sua perceção de preferências (localização, relação funcional do produto, etc) que constituem o construto Fatores Preferenciais. E destes, como coeficientes de determinação mais significativos das variáveis explicativas foram encontrados a localização próxima e a relação funcional pelo que fica demonstrado que a variabilidade da motivação é significativamente dependente, principalmente da localização e da relação produto e respetivo sistema de produção. Da presente investigação podemos ainda concluir que tendo sido identificadas as duas variáveis mais significativas na variação das motivações de compra dos consumidores para o retalho independente centenário - a localização próxima e a relação funcional existente entre o tipo de produtos oferecidos e o seu modo de produção - e após aprofundarmos a associação destas variáveis com as variáveis de perfil (sexo, idade e nível de instrução) dos consumidores se constata que as mulheres, ainda que de forma não muito significativa, valorizam mais o fator localização e o fator da relação existente entre o tipo de produtos oferecidos e o seu modo de produção que os homens. Curiosamente, constata-se também que o fator localização é mais relevante para os consumidores da faixa etária de 35 a 45 anos, o mesmo acontecendo para o fator da relação existente entre o tipo de produtos oferecidos e o seu modo de produção. Quanto ao nível de instrução constata-se que os consumidores de formação superior são os que mais valorizam relação existente entre o tipo de produtos oferecidos e o seu modo de produção não sendo importante para estes o fator localização.

\section{Referências bibliográficas}

Adger, W. N. (2000). Social and ecological resilience: are they related? Progress in Human Geography, 24(3), 347-364. https://doi.org/10.1191/030913200701540465

Altintas, G. \& Royer, I. (2009). Renforcement de la résilience par un apprentissage postcrise : une étude longitudinale sur deux périodes de turbulence.M@n@gement, 12, 266-293. https://doi.org/10.3917/mana.124.0266

Arregle, J. L., Hitt, M. A., Sirmon, D. G., \& Very, P. (2007). The development of organizational social capital: Attributes of family firms. Journal of management studies, 44(1), 73-95. https://doi.org/10.1111/j.1467-6486.2007.00665.x

Arthur, W. B. (1999). Complexity and the economy. science, 284(5411), 107-109. https://doi.org/10.1126/science.284.5411.107

Ballantine, P. W., Jack, R., \& Parsons, A. G. (2010). Atmospheric cues and their effect on the hedonic retail experience. International Journal of Retail \& Distribution Management. 38(8), 641-653. https://doi.org/10.1108/09590551011057453

Barreta, J. (2012). Comércio de proximidade e regeneração urbana. CIP, Lisboa. 
Bell, D. R., Corsten, D., \& Knox, G. (2010). Unplanned buying on shopping trips. Marketing Science Institute. https://www.msi.org/wpcontent/uploads/2020/06/MSI_Report 10-109.pdf

Berman, B., \& Evan, J. R. (1995). Retail Management (6. ${ }^{a}$ ed.). Pearson Education Limited.

Bonanno, G. A. (2004). Loss, Trauma, and Human Resilience: Have We Underestimated the Human Capacity to Thrive After Extremely Aversive Events? American Psychologist, 59(1), 20-28. https://doi.org/10.1037/0003-066X.59.1.20

Byun, S.-E., \& Mann, M. (2011). The Influence of Others: The Impact of Perceived Human Crowding on Perceived Competition, Emotions, and Hedonic Shopping Value. Clothing and Textiles Research Journal, 29(4), 284-297. https://doi.org/10.1177/0887302X11422820

Callaway, D. S., Newman, M. E. J., Strogatz, S. H., \& Watts, D. J. (2000) Network Robustness and Fragility: Percolation on Random Graphs. Physical Review Letters, 85(25), 5468-5471. https://doi.org/10.1103/PhysRevLett.85.5468

Carpenter,S., Walker, B., Anderies, J. M., \& Abel, N. (2001). From metaphor to measurement: resilience of what to what? Ecosystems, 4, 765-781. https://doi.org/10.1007/s10021-001-0045-9

Collins, A., Kavanagh, E., Cronin, J., \& George, R. (2014). Money, mavens, time and price search: modeling the joint creation of utilitarian and hedonic value in grocery shopping. Journal of Marketing Management, 30(7-8), 719-746. https://doi.org/10.1080/0267257X.2013.839572

Conant, J., \& White, J. (1999). Marketing programme planning, process benefits, e store performance: an initial study among small retail firms. Journal of Retailing 75(4), 525-541. https://doi.org/10.1016/S0022-4359(99)00017-2

Coutinho, C. P. (2011). Metodologia de Investigação em Ciências Sociais e Humanas:Teoria e Prática, Almedina.

Coutu, D. L. (2002). How resilience works. Harvard business review, 80(5), 46-56.

Cox, A. D., Cox, D., \& Anderson, R.D. (2005). Reassessing the pleasures of store shopping. Journal of Business Research, 58(3), 250-259. https://doi.org/10.1016/S0148-2963(03)00160-7

Creusen, M. E. H., \& Schoormans, J. P. L. (2005). The Different Roles of Product Appearance in Consumer Choice. Journal of Product Innovation Management, 22(1), 63-81. https://doi.org/10.1111/j.0737-6782.2005.00103.x

Dalziell, E. P., \& Mcmanus, S. T. (2004). Resilience, vulnerability, adaptive capacity: implications for system performance. In International Forum for Engineering Decision Making (IFED), Stoos, Switzerle. http://hdl.handle.net/10092/2809

Danes S.M., Stafford K., Haynes G., \& Amarapurkar S. S. (2009). Family Capital of Family Firms: Bridging Human, Social, and Financial Capital. Family Business Review, 22(3), 199-215. https://doi.org/10.1177\%2F0894486509333424

Davies, G., \& Harris, K. (1990). The Independent Retailer. In Small Business (pp. 1-15). Palgrave, London. 
Dawson, J. (1983). Independent retailing in Great Britain: dinosaur or chameleon. Retail e Distribution Management, 11(3), 29-32. https://doi.org/10.1108/eb018188

Dawson, S. J., Bloch, P. H., \& Ridgway, N. M. (1990). Shopping motives, emotional states and retail outcomes. Journal of Retailing, 66(4), 408-427.

De Carolis, D. M., Yang, Y., Deeds, D. L., \& Nelling, E. (2009). Weathering the storm: the benefit of resources to high-technology ventures navigating adverse events. Strategic Entrepreneurship Journal, 3(2), 147-160. https://doi.org/10.1002/sej.68

Desmet, P., \& Hekkert, P. (2007). Framework of product experience. International journal of design, 1(1). http://www.ijdesign.org/index.php/IJDesign/article/view/66

Fiksel, J. (2006). Sustainability and resilience: toward a systems approach. Sustainability: Science, Practice and Policy, 2(2), 14-21. https://doi.org/10.1080/15487733.2006.11907980

Folke, C., Carpenter, S., Elmqvist, T., Gunderson, L., Holling, C. S., \& Walker, B. (2002). Resilience and sustainable development: building adaptive capacity in a world of transformations. AMBIO: A journal of the human environment, 31(5), 437440. https://doi.org/10.1579/0044-7447-31.5.437

Gallopín, G. C. (2006). Linkages between vulnerability, resilience, and adaptive capacity. Global environmental change, 16(3), 293-303. https://doi.org/10.1016/j.gloenvcha.2006.02.004

Gibbs, M. T. (2009). Resilience: What is it and what does it mean for marine policymakers?. Marine Policy, 33(2), 322-331. https://doi.org/10.1016/j.marpol.2008.08.001

Goble, G., Fields, H., \& Cocchiara, R. (2002). Resilient infrastructure: Improving your business resilience. IBM Global Services.

Haimes, Y. Y., Crowther, K., \& Horowitz, B. M. (2008). Homeland security preparedness: Balancing protection with resilience in emergent systems. Systems Engineering, 11(4), 287-308. https://doi.org/10.1002/sys.20101

Hamel, G., \& Valikangas, L. (2003) The quest for resilience. Harvard Business Review, $81,52-63$.

Hamrouni, A. D., \& Touzi, M. (2011). Technique of collage for store design atmospherics. Qualitative Market Research: An International Journal, 14(3), 304323. https://doi.org/10.1108/13522751111137523

Hassenzahl, M., Schöbel, M., \& Trautmann, T. (2008). How motivational orientation influences the evaluation and choice of hedonic and pragmatic interactive products: The role of regulatory focus. Interacting with Computers, 20(4-5), 473-479. https://doi.org/10.1016/j.intcom.2008.05.001

He, Y. (2008). A novel approach to emergency management of wireless telecommunication system (Doctoral dissertation, University of Saskatchewan). http://hdl.handle.net/10388/etd-06112008-114820 
Hui, S. K., Inman, J. J., Huang, Y., \& Suher, J. (2013). The effect of in-store travel distance on unplanned spending: Applications to mobile promotion strategies. Journal of Marketing, 77(2), 1-16. https://doi.org/10.1509/jm.11.0436

Ignatiadis, I., \& Nandhakumar, J. (2007). The impact of enterprise systems on organizational resilience. Journal of Information Technology, 22(1), 36-43. https://doi.org/10.1057\%2Fpalgrave.jit.2000087

Jin, B., \& Kim, J. O. (2003). A typology of Korean discount shoppers: shopping motives, store attributes, and outcomes. International journal of service Industry Management, 14(4), 396-419. https://doi.org/10.1108/09564230310489240

Kirby, D. A. (1974). The decline and fall of the smaller retail outlet: A geographical study. Retail and Distribution Management, 2(1),14-18. https://doi.org/10.1108/eb017765.

Kirby, D. A., \& Law, D. C. (1981). The birth and death of small retail units in Britain: A preliminary study. Retail and Distribution Management, 9(1), 16-19. https://doi.org/10.1108/eb018085

Kotler, P., \& Dubois, B. (1995). Marketing Management. Publi Union.

Lachman, M. L., \& Brett, D. L. (2013). Generation Y: Shopping and entertainment in the digital age. Urban Land Institute.

Lengnick-Hall, C. A., \& Beck, T. E. (2005). Adaptive fit versus robust transformation: How organizations respond to environmental change. Journal of Management, 31(5), 738-757. https://doi.org/10.1177\%2F0149206305279367

Lengnick-Hall, C. A., \& Beck, T. E. (2009). Resilience capacity and strategic agility: Prerequisites for thriving in a dynamic environment. San Antonio, TX: UTSA, College of Business.

Mallak, L. A. (1999, July). Toward a theory of organizational resilience. In PICMET'99: Portland International Conference on Management of Engineering and Technology. Proceedings Vol-1: Book of Summaries (IEEE Cat. No. 99CH36310). https://doi.org/10.1109/PICMET.1999.808142

McGee, J. E., \& Peterson, M. (2000). Toward the development of measures of distinctive competencies among small independent retailers. Journal of small business management, 38(2), 19-33.

Megicks, P. (2001). Competitive strategy types in the UK independent retail sector. Journal of Strategic Marketing, 9(4), 315-328. https://doi.org/10.1080/09652540110079029

Miller, R. (1981). Strategic pathways to growth in retailing. The Journal of Business Strategy, 1(3), 16-29.

Mokhlis, S., Kamarudin, A. R., \& Yassin, S. (2003). Correlates of shopping orientation with retail choice decisions among young consumers. Jurnal Pengurusan, 22, 47-66. https://ejournal.ukm.my/pengurusan/article/view/1313 
Morschett, D., Swoboda, B., \& Foscht, T. (2005). Perception of store attributes and overall attitude towards grocery retailers: The role of shopping motives. The International Review of Retail, Distribution and Consumer Research, 15(4), 423447. https://doi.org/10.1080/09593960500197552

Morschett, D., Swoboda, B., \& Schramm-Klein, H. (2005). Shopping orientations as determinants of attitude towards food retailers and perception of store attributes. In K. M. Ekstrom \& H. Brembeck (Eds.), E-European Advances in Consumer Research Volume 7 (pp. 160-167). Association for Consumer Research, Goteborg, Sweden. https://www.acrwebsite.org/volumes/13673

Moschis, G., Curasi, C., \& Bellenger, D. (2004). Patronage motives of mature consumers in the selection of food and grocery stores. Journal of Consumer Marketing, 21(2), 123-133. https://doi.org/10.1108/07363760410525687

Moutinho, L., Dionísio, P., Rodrigues, J. V., \& Pereira, H. G. (2012). Marketing Trends. Marketing FutureCast Lab, ISCTE \& IUL, Bnomics.

Patterson, E. S., Woods, D. D., Cook, R. I., \& Render, M. L. (2007). Collaborative crosschecking to enhance resilience. Cognition, Technology \& Work, 9, 155-162.

https://doi.org/10.1007/s10111-006-0054-8

Rosa, C. A. (2014). Modelização Sincrónica da Qualidade de Serviço. Edição IADE. Lisboa

Rose, A., \& Liao, S. Y. (2005). Modeling regional economic resilience to disasters: A computable general equilibrium analysis of water service disruptions. Journal of Regional Science, 45(1), 75-112. https://doi.org/10.1111/j.0022-4146.2005.00365.x

Rouse, W. B. (2005). Enterprises as systems: Essential challenges and approaches to transformation. Systems Engineering, 8(2), 138-150.

https://doi.org/10.1002/sys.20029

Rousseau, J. A. (2001). Dicionário da Distribuição. AJE, Lisboa.

Rousseau, J. A. (2008). Manual de Distribuição. Principia, Lisboa.

Rousseau, J. A. (2011, julho 13). $3 .{ }^{\circ}$ Gene do ADN da Distribuição: Resiliência. Revista Hipersuper. https://bit.ly/3p3KhTw

Ryu, K., Han, H., \& Jang, S. S. (2010). Relationships among hedonic and utilitarian values, satisfaction and behavioral intentions in the fast-casual restaurant industry. International Journal of Contemporary Hospitality Management, 22(3), 416-432. https://doi.org/10.1108/09596111011035981

Scott, M., Sorcinelli, G., Gutierrez, P., Moffatt, C., \& DesAutels, P. (2006, June). CONFERENCEXP: an enabling technology for organizational resilience. In IFIP International Working Conference on the Transfer and Diffusion of Information Technology for Organizational Resilience (pp. 219-227). Springer, Boston, MA. https://doi.org/10.1007/0-387-34410-1_15

Sheffi, Y., \& Rice Jr, J. B. (2005). A supply chain view of the resilient enterprise. MIT Sloan management review, 47(1), 41-48.

Starr, R., Newfrock, J., \& Delurey, M. (2003). Enterprise resilience: managing risk in the networked economy. Strategy and business, 30, 1-10. https://bit.ly/3F5qAAf 
Stevenson, H. E., \& Jarillo, J. C. (1990). A paradigm of entrepreneurship: entrepreneurial management. Strategic Management Journal, 11(5), 17-27.

Stopford, J. M., \& Baden-Fuller, C. W. (1994). Creating corporate entrepreneurship. Strategic management journal, 15(7), 521-536. https://doi.org/10.1002/smj.4250150703

Stoltman, J. J., Gentry, J. W., \& Anglin, K. A. (1991). Shopping choices: the case of mall choice. In R. H. Holman \& M. R. Solomon (Eds.), Advances in Consumer Research Volume 18, (pp. 434-440). ACR Association for Consumer Research.

Thorne, M. L. (2000). Interpreting corporate transformation through failure. Management Decision, 38(5), 303-314. https://doi.org/10.1108/00251740010340481

Weick, K. E., \& Sutcliffe, K. M. (2011). Managing the unexpected: Resilient performance in an age of uncertainty (Vol. 8). John Wiley \& Sons.

Wreathall, J. (2006). Developing models for measuring resilience. John Wreathall \& Co., Inc., Dublin, Ohio.

Van Kenhove, P., De Wulf, K., \& Van Waterschoot, W. (1999). The impact of task definition on store-attribute saliences and store choice. Journal of Retailing, 75(1), 125-137. https://doi.org/10.1016/S0022-4359(99)80007-4

Zhang, W. (2008). Resilience engineering - a new paradigm e technology for systems. Canada: University of Saskatchewan. 